\title{
Age-related spontaneous lacrimal keratoconjunctivitis is accompanied by dysfunctional T regulatory cells
}

\author{
TG Coursey ${ }^{1}$, F Bian $^{1}$, M Zaheer ${ }^{1}$, SC Pflugfelder ${ }^{1}$, EA Volpe $^{1}$ and CS de Paiva ${ }^{1}$
}

In both humans and animal models, the development of Sjögren syndrome (SS) and non-SS keratoconjunctivitis sicca (KCS) increases with age. Here, we investigated the ocular surface and lacrimal gland (LG) phenotype of NOD.B10.H2 ${ }^{b}$

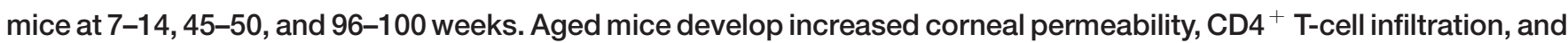
conjunctival goblet cell loss. Aged mice have LG atrophy with increased lymphocyte infiltration and inflammatory cytokine levels. An increase in the frequency of $\mathrm{CD} 4{ }^{+} \mathrm{Foxp}^{+}{ }^{+}$T regulatory cells (Tregs) was observed with age in the cervical lymph node (CLN), spleen, and LG. These $\mathrm{CD} 4{ }^{+} \mathrm{CD} 25^{+}$cells lose suppressive ability, while maintaining expression of Foxp3 (forkhead box P3) and producing interleukin-17 (IL-17) and interferon- $\gamma$ (IFN- $\gamma$ ). An increase of Foxp ${ }^{+} \mathrm{IL}-17^{+}$or Foxp $3^{+} \mathrm{IFN}-\gamma^{+}$cells was observed in the LG and LG-draining CLN. In adoptive transfer experiments, recipients of either purified Tregs or purified Teffector cells from aged donors developed lacrimal keratoconjunctivitis, whereas recipients of young Tregs or young T effector cells failed to develop disease. Overall, these results suggest inflammatory cytokine-producing $\mathrm{CD}_{4}^{+}{ }^{-} \mathrm{Oxp}^{+}$cells participate in the pathogenesis of age-related ocular surface disease.

\section{INTRODUCTION}

The aging process at the ocular surface is poorly understood. In Sjögren syndrome (SS) and non-SS keratoconjunctivitis sicca (KCS), as with most other autoimmune diseases, age is a major risk factor. The processes responsible for aging, in general, remain controversial and there is no accepted unifying theory. Several theories have been proposed to explain the aging process. These include "error theories" in which aging occurs in response to DNA damage, posttranslational modification, oxidative, or metabolic stress. ${ }^{1-3}$ Other theories include "programmed theories" in which genes are switched on or off with age (programmed longevity) or in which the biological clock responds to hormones that control the aging process. ${ }^{1-3}$ Another programmed theory is one in which immunological responses become dysregulated with age, leading to susceptibility to infectious disease or increased occurrence of autoimmune disease. ${ }^{4-6}$

Both SS and non-SS KCS have been shown to increase in prevalence with age. ${ }^{7,8}$ Aging induces structural changes in the lacrimal gland (LG), including atrophy of acinar cells and fibrosis. Preliminary studies suggest that this fibrosis and gland dysfunction is related to inflammatory disease. ${ }^{9,10}$ In humans, there is a progressive increase of lymphocytes in the LGs beginning at age of $\sim 40$ years. ${ }^{7,8}$ Findings in animal models (in both rat and mouse) parallel human disease with progressive changes beginning at $\sim 12$ months of age. ${ }^{11,12}$ An increase in the numbers and inflammatory cytokine production of $\mathrm{CD} 4^{+}$ and $\mathrm{CD} 8{ }^{+} \mathrm{T}$ cells and $\mathrm{B}$ cells was reported in the LG of aged C57BL/6 mice by our group. ${ }^{13}$

In addition to increased activity of effector cells, a decrease in immune suppression by $\mathrm{CD} 4{ }^{+} \mathrm{CD} 25^{+} \mathrm{Foxp}^{+}$T regulatory cells (Tregs) has been observed in some autoimmune models with age. In many instances the loss of suppression occurs with unchanged or increased numbers of Tregs. ${ }^{14,15}$ It has been well documented that Tregs and Thelper (Th) cells, both Th1 and Th17 cells, are major players in many autoimmune diseases, including ocular surface diseases like KCS. ${ }^{16-19}$ It is also known that the phenotype of these cells is plastic, and dysregulation is

${ }^{1}$ Ocular Surface Center, Department of Ophthalmology, Cullen Eye Institute, Baylor College of Medicine, Houston, Texas, USA. Correspondence: CS de Paiva (cintiadp@bcm.edu) 
responsible for the pathogenesis of several autoimmune diseases. ${ }^{20-22}$ Several groups have reported that Tregs become dysfunctional with age. ${ }^{23,24}$ Others have reported that CD4 ${ }^{+}$ $\mathrm{CD}_{25}{ }^{+}$Foxp $^{+}$Tregs convert to interleukin-17 (IL-17)producing effector cells. ${ }^{20,25}$ These cells maintain suppressive ability and produce moderate amounts of IL-17 and interferon$\gamma($ IFN- $\gamma$ ) while maintaining expression of Foxp3 (forkhead box P3). ${ }^{26}$ IL- $17^{+}$Foxp3 ${ }^{+} \mathrm{T}$ cells express high levels of Treg markers, Foxp3, CD25, glucocorticoid-induced tumor necrosis factor receptor (GITR), and cytotoxic T-lymphocyte associated protein-4 (CTLA-4). However, they also express retinoic acid receptor-related orphan receptor- $\gamma \mathrm{t}(\mathrm{ROR} \gamma \mathrm{t}), \mathrm{IL}-17$, and increased levels of inducible T-cell costimulator (ICOS), chemokine receptor 6 (CCR6), and IFN- $\gamma .{ }^{27}$

Various mouse models have been used to model the pathogenesis of SS, such as NZB/W F1, the TGF- $\beta 1 \mathrm{KO}$, $\mathrm{MRL} / \mathrm{lpr}, \mathrm{NFS} / \mathrm{sld}$, the CD25KO, and the nonobese diabetic (NOD) mouse. ${ }^{28-31}$ The NOD mouse has the greatest similarity to human disease as the development of adenitis is accompanied by decreased secretory function in the lacrimal and salivary glands. In this study we employ the NOD.B10-H2 ${ }^{\text {b }}$ mice. This a congenic strain in which the major histocompatibility complex (MHC) of NOD was replaced by the MHC of C57BL/10 mice. These mice fail to develop insulitis and type 1 diabetes, but continue to show a mild SS-like disease. ${ }^{32}$

Here, we describe a spontaneous increase in ocular surface and LG immunopathology with increasing age. Increased inflammation was accompanied by increased numbers of $\mathrm{CD} 4{ }^{+} \mathrm{CD} 25^{+}$Foxp $3^{+}$T cells compared with young controls. $\mathrm{CD} 4{ }^{+} \mathrm{CD} 25^{+}{ }^{+}$oxp $3{ }^{+} \mathrm{T}$ cells in old mice were dysfunctional and expressed an altered IL- $17^{+}$IFN- $\gamma^{+}$Foxp $3^{+}$phenotype while maintaining Foxp3 expression. This the first study to describe a subset of $\mathrm{CD} 4{ }^{+} \mathrm{CD} 25^{+} \mathrm{Foxp}^{+}$that spontaneously develop with age, lose suppressive ability, produce significant amounts of inflammatory cytokines, and actively participate in development of lacrimal KCS.

\section{RESULTS}

\section{Aged male NOD.B10. $2^{b}$ mice have a spontaneous dry eye ocular surface phenotype}

Previous studies examining models of SS have focused on LG pathology. Here, we examined the ocular surface disease phenotype of aged NOD.B10.H2 ${ }^{\mathrm{b}}$ mice. Hallmarks of dry eye pathology include increased corneal permeability, CD4 ${ }^{+} \mathrm{T}$-cell infiltration, conjunctival goblet cell loss, and increased expression of inflammatory cytokines. ${ }^{16,33,34}$ To assess corneal permeability, the fluorescent Oregon Green Dextran (OGD) dye was instilled in each eye, as previously described. ${ }^{35}$ OGD uptake was significantly increased with age (at both 45 and 96 weeks; Figure 1a, c). Confirming dry eye pathology, an agerelated increase in $\mathrm{CD}_{4}{ }^{+} \mathrm{T}$-cell infiltration was observed in the conjunctiva by immunohistochemistry (Figure $\mathbf{1} \mathbf{b}, \mathbf{d}$ ). In agreement with these findings, a significant decrease in mucin filled conjunctival goblet cells was observed with increasing age as measured by periodic acid-Schiff staining (Figure 1e). As expected, an increase in the gene expression of the inflammatory cytokines, IFN- $\gamma$ and IL-17A, and MHC class II was observed in the conjunctiva with age by quantitative PCR. Conjunctival goblet cell homeostatic promoting factor, IL-13, did not change with age (Figure 1f). These results indicate a progressive increase in ocular surface pathology with advanced age in NOD.B10.H2 ${ }^{\mathrm{b}}$ mice.

To determine which populations of lymphocytes were producing inflammatory cytokines, flow cytometry experiments were performed in the conjunctiva and the cervical lymph node (CLN) of mice at 7-14 and 45-50 weeks. As seen in Supplementary Figure $\mathrm{S1a}$ online, $\mathrm{CD} 4{ }^{+} \mathrm{T}$ cells and CD8 ${ }^{+} \mathrm{T}$ cells are predominant lymphocytes, followed by other CD $45^{+}$ cells (presumably B cells and myeloid cells). Natural killer cells, natural killer $\mathrm{T}$ cells, and $\gamma \delta \mathrm{T}$ cells make up the other populations in these tissues. Only $\mathrm{CD}^{+}, \mathrm{CD}^{+}$, and $\gamma \delta$ T cells make IFN- $\gamma$ and IL-17 in these tissues (Supplementary Figure S1b).

\section{Aged male NOD.B10.H2 ${ }^{b}$ mice have LG pathology}

Next, we examined the LG pathology that accompanies age in NOD.B10.H2 ${ }^{b}$ mice. Gross examination of the LGs showed LG atrophy and a progressive loss of cellular components, including acinar cells with aging (Figure $2 \mathbf{a}$ ). To quantify LG pathology, inflammation scores were assigned to LG sections according to the parameters stated in the Methods sections (Figure 2c), and to account the size of foci we calculated the foci area as a percentage of the total glandular area (Figure 2d). In order to rule out strain specificity of the observed phenotype, LGs were examined from aged male C57BL/6 mice that share the same $\mathrm{H} 2{ }^{\mathrm{b}}$ haplotype. As seen in Figure $2 \mathbf{b}-\mathbf{d}, \mathrm{C} 57 \mathrm{BL} / 6$ mice also develop spontaneous LG pathology with increased age but at a slower rate. These results suggest that C57BL/6 mice develop a disease phenotype similar to NOD.B10.H2 ${ }^{\mathrm{b}}$ mice, but the genetic predisposition of NOD.B10.H2 ${ }^{\mathrm{b}}$ mice accelerates disease, making this a useful model for aging studies (Figure 2c). Paradoxically, we observed that epidermal growth factor concentration and tear volume (measured with the phenol red cotton-thread technique) increased with age in NOD.B10.H2 ${ }^{\mathrm{b}}$ mice (Figure $\mathbf{2 e , f}$ ), as previously reported in another aged inbred strain. ${ }^{13}$ In order to assess the inflammatory state of aged NOD.B10. $2_{2}{ }^{b}$ mice, we examined the expression of inflammatory cytokines and the infiltration of lymphocytes into the LG. The gene expression of IFN- $\gamma$, IL$17 \mathrm{~A}, \mathrm{IL}-1 \beta$, and tumor necrosis factor $-\alpha$ (TNF- $\alpha$ ) significantly increased with age in the LG. Interestingly, IL-13 also increased, indicating not only Th1 and Th17-associated cytokines but also Th2-associated cytokines in the LG (Figure 2g). In agreement, increased infiltration of $\mathrm{CD}^{+}{ }^{+}, \mathrm{CD}^{+}{ }^{+}$, and $\mathrm{B} 220^{+}$cells was observed in the LG with age by immunohistochemistry and this was quantified by flow cytometry (Figure $\mathbf{2 h}, \mathbf{i}$ ). These observations led to the conclusion that age in NOD.B10. $\mathrm{H} 2{ }^{\mathrm{b}}$ mice leads to LG pathology similar to the one observed in dry eye disease (DED) and SS patients.

\section{Systemic inflammation in NOD.B10. $2^{\mathrm{b}}$ mice}

We sought to determine whether inflammation in NOD.B10. $2_{2}{ }^{b}$ mice was exclusive to the eye or LG. To address 
a

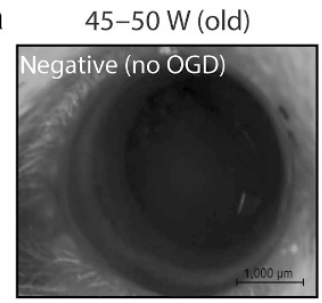

b

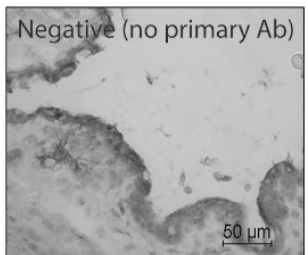

$7-14$ W (young)
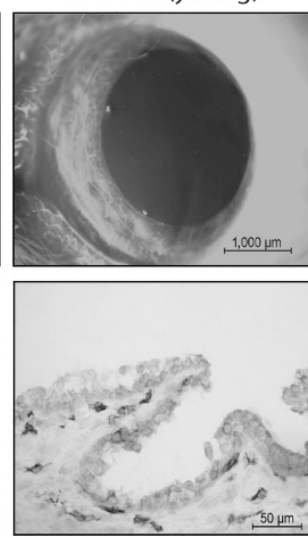

$45-50 \mathrm{~W}$ (old)
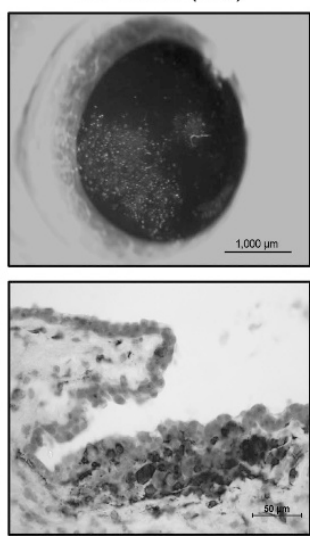

96-100 W (old)
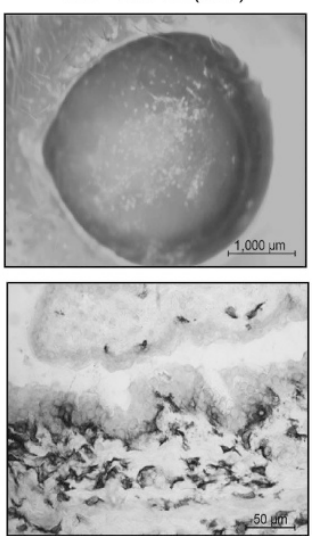
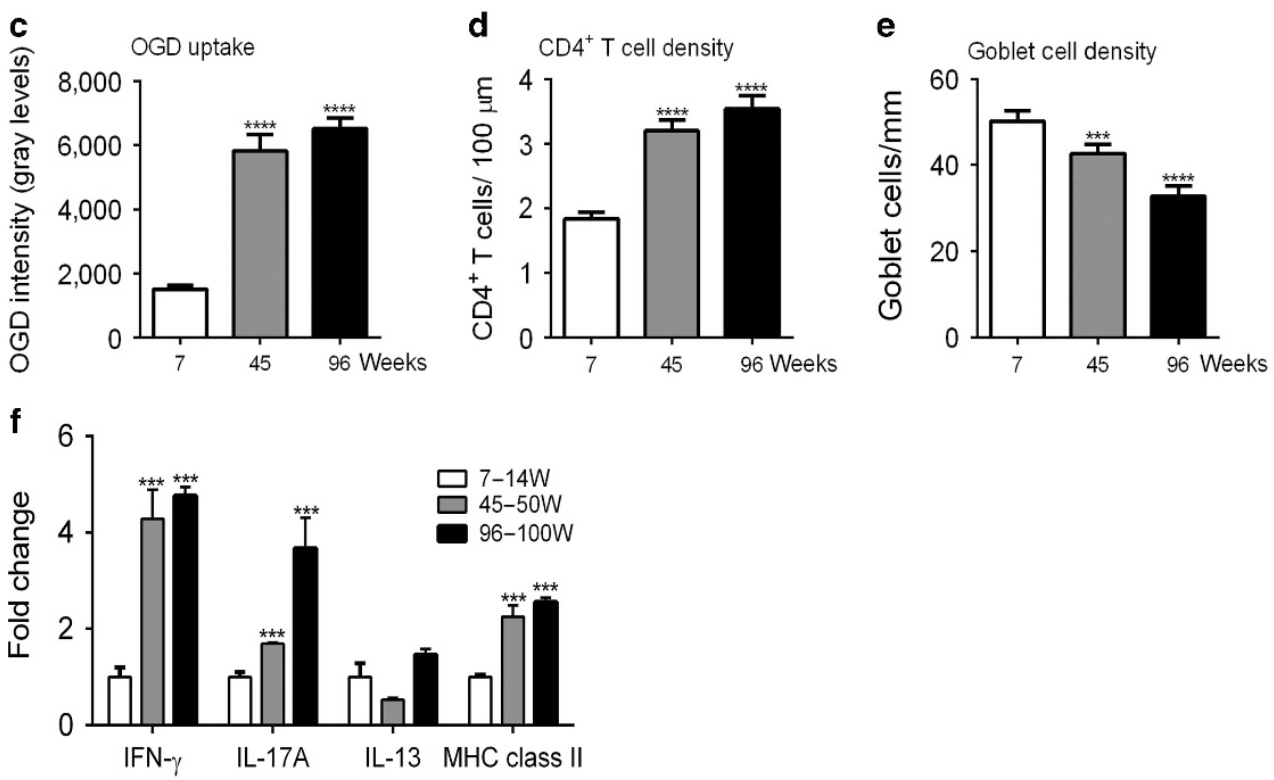

Figure 1 Aged male NOD.B10. $2^{\mathrm{b}}$ mice have a spontaneous dry eye phenotype. (a) Representative pictures of the corneas stained with Oregon Green dextran (OGD) of mice at 7-14, 45-50, and 96-100 weeks. (b) Representative images of conjunctiva frozen sections immunostained for CD4 (in red/ brown) used to generate the bar graph in (d). (c) Corneal OGD fluorescence intensity score. Bar graphs show means \pm s.d. of three independent experiments with five animals per experiment (10 eyes per experiment, yielding a final sample of 30 eyes per group). (d) CD4 ${ }^{+} \mathrm{T}$ cells infiltrating the conjunctival epithelium. Bar graphs show means \pm s.d. of two independent experiments with two to three animals per age, yielding a final sample of five left eyes for each group. (e) Number of $\mathrm{PAS}^{+}$conjunctival goblet cells counted in paraffin-embedded sections expressed as number per mm. Bar graphs show means \pm s.d. of two independent experiments with two to three animals per group, yielding a final sample of five right eyes for each group. (f) Relative fold expression changes of interferon- $\gamma$ (IFN- $\gamma$ ), interleukin (IL)-17A, IL-13, and major histocompatibility complex (MHC) class II mRNA in the conjunctiva. Bar graphs show means \pm s.d. of six samples per age (the experiment was repeated twice with similar results). Parametric $t$-test statistical tests were used to make comparisons between age groups. ${ }^{\star \star} P<0.01,{ }^{* \star *} P<0.001$ for comparison between age groups. PAS, periodic acidSchiff; W, week.

this, we measured the levels of cytokines in the serum of NOD.B10.H2 $2^{\mathrm{b}}$ mice at $7-14$ and $96-100$ weeks. A significant increase in the serum levels of IFN- $\gamma$ and IL-17A, cytokines produced by Th1 and Th17 cells, respectively, was observed (Figure 3c,d). The levels of the Th2-associated cytokines, IL-4 and IL-13, did not change (Figure 3a,b). To further examine this, we determined the frequency of splenic $\mathrm{CD} 4{ }^{+} \mathrm{T}$ cells that produced IFN- $\gamma$ or IL-17A in mice at 7-14 and $45-50$ weeks. A significant increase in the frequency of $\mathrm{CD} 4{ }^{+} \mathrm{IFN}-\gamma^{+}$and $\mathrm{CD} 4{ }^{+} \mathrm{IL}-17^{+}$was observed in the spleen with age by flow cytometry (Figure 3e,f). This indicates that a Th1 and Th17 systemic immune response occurs with age in NOD.B10.H2 mice.

\section{Aged NOD.B10.H2 ${ }^{\mathrm{b}}$ mice have an increase in $\mathrm{CD} 4^{+}{ }^{+}$oxp $3^{+}$ cells}

In spite of increased inflammation, a significant increase of $\mathrm{CD} 4^{+}$Foxp $^{+}$was observed in aged NOD.B10.H2 ${ }^{\mathrm{b}}$ mice. An increase in the infiltration of Foxp $3^{+}$cells was observed in the LG as seen by immunohistochemistry with age (Figure 4a). To quantify this, the percentage of $\mathrm{CD}^{+}{ }^{+} \mathrm{Foxp}^{+}$cells was determined by flow cytometry in LG, submandibular 
CLN, and spleens of NOD.B10.H2 ${ }^{\mathrm{b}}$ mice at $7-14$ and 45-50 weeks. A significant increase in $\mathrm{CD}^{+}{ }^{+}$Foxp $3^{+}$occurs with age in the LG, CLN, and spleen (Figure $4 \mathbf{b}$ ). We also examined the effect of age on other glands, such as submandibular gland, in these mice. No changes in clinical inflammation scores or cellular infiltration with age were observed in the submandibular gland (data not shown). Interestingly, $\mathrm{CD} 4{ }^{+} \mathrm{Foxp}^{+}$have the highest frequency in a

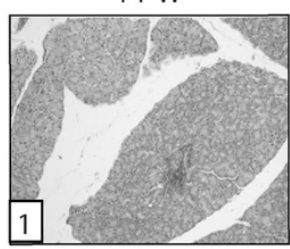

$45 \mathrm{~W}$

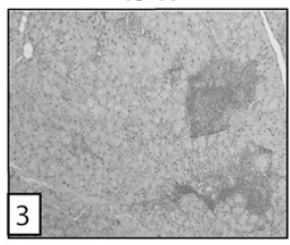

$96 \mathrm{~W}$

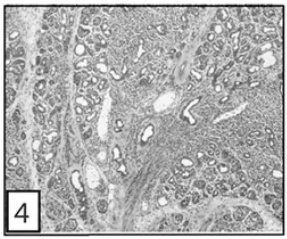

e Tear volume

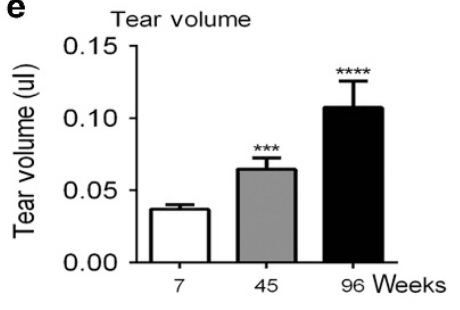

b
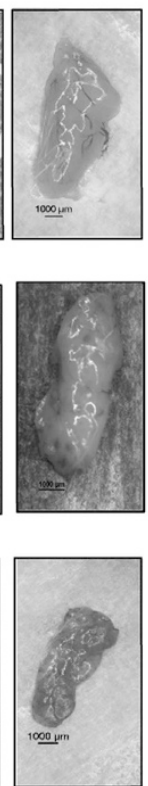

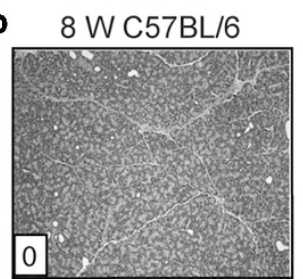

$41 \mathrm{~W} \mathrm{C57BL/6}$

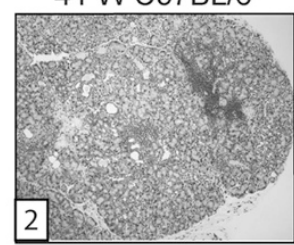

96 W C57BL/6

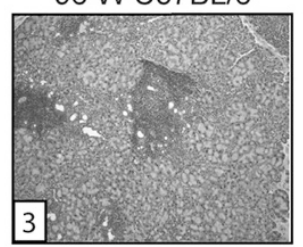

f

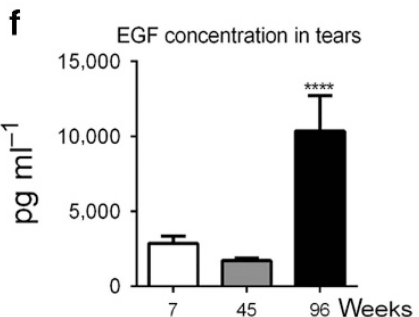

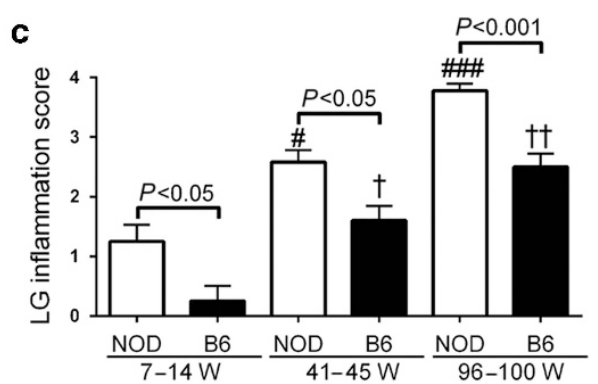
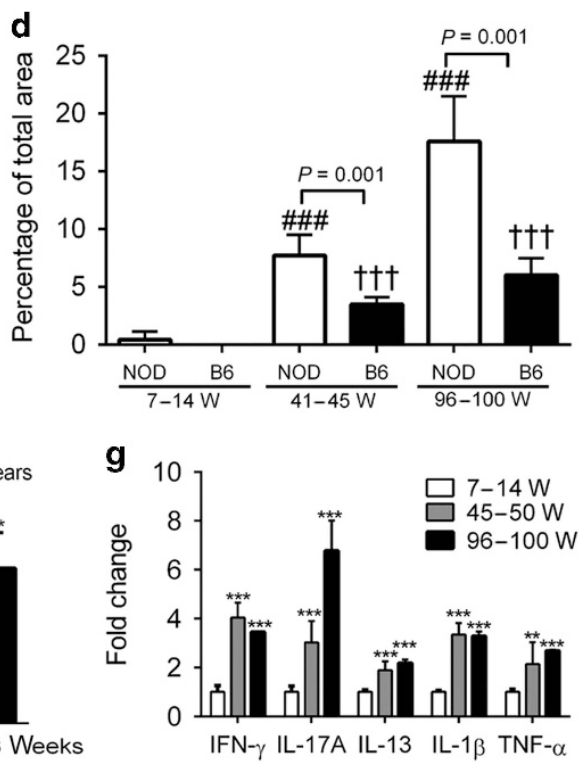

h
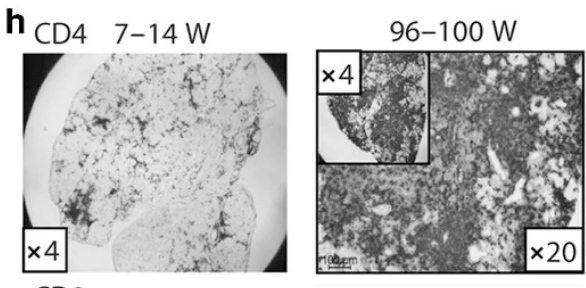

No primary Ab control

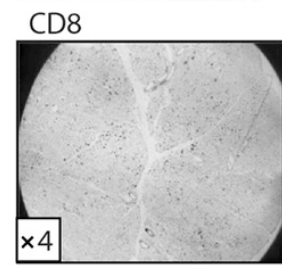

B220
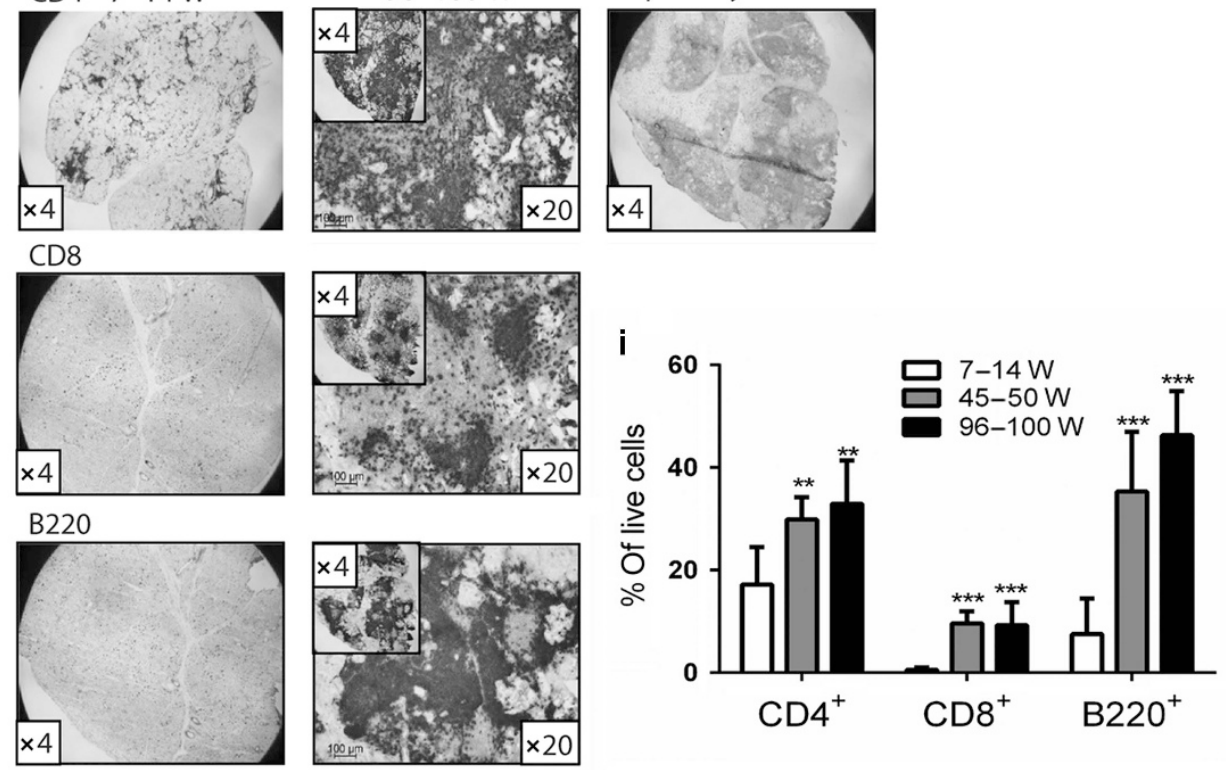
the aged LG. The LG-draining CLN have increased frequency of $\mathrm{CD} 4{ }^{+}$Foxp $3^{+}$cells with age, whereas the spleen has a modest increase in frequency in $\mathrm{CD} 4{ }^{+} \mathrm{Foxp}^{+}$cells (Figure $4 \mathbf{b}$ ). To quantify the expression of Foxp3, the mean fluorescence intensity of $\mathrm{CD} 4{ }^{+}$Foxp $^{+}$cells was determined. All tissues examined had a significant increase in the expression of Foxp3 (Figure 4c). Paradoxically, the increase of $\mathrm{CD} 4{ }^{+}$Foxp $3^{+}$cells occurs despite increased disease severity, suggesting dysfunction of the suppressive ability of these cells.

\section{Aged mice have an increase in inflammatory cytokine-producing CD4 ${ }^{+}$Foxp3 ${ }^{+}$cells}

This prompted us to examine the population of CD $4^{+} \mathrm{Foxp}^{+}$ IL- $17^{+}$or $\mathrm{CD}^{+}{ }^{+}$Foxp $^{+}{ }^{+}$IFN- $\gamma^{+}$cells in the LG, CLN, and spleens of mice at 7-14 and 45-50 weeks. As seen in representative plots (Figure $\mathbf{4 d}$, e) and the combined data (Figure 4g), an increase in Foxp $3^{+} \mathrm{IL}_{-1} 7^{+}$and Foxp ${ }^{+}$ IFN- $\gamma^{+}$was observed in the LG and CLN. Only an increase in the Foxp $3^{+}$IFN- $\gamma^{+}$population was observed in the spleen with age. These results suggest that Tregs maintain Foxp3
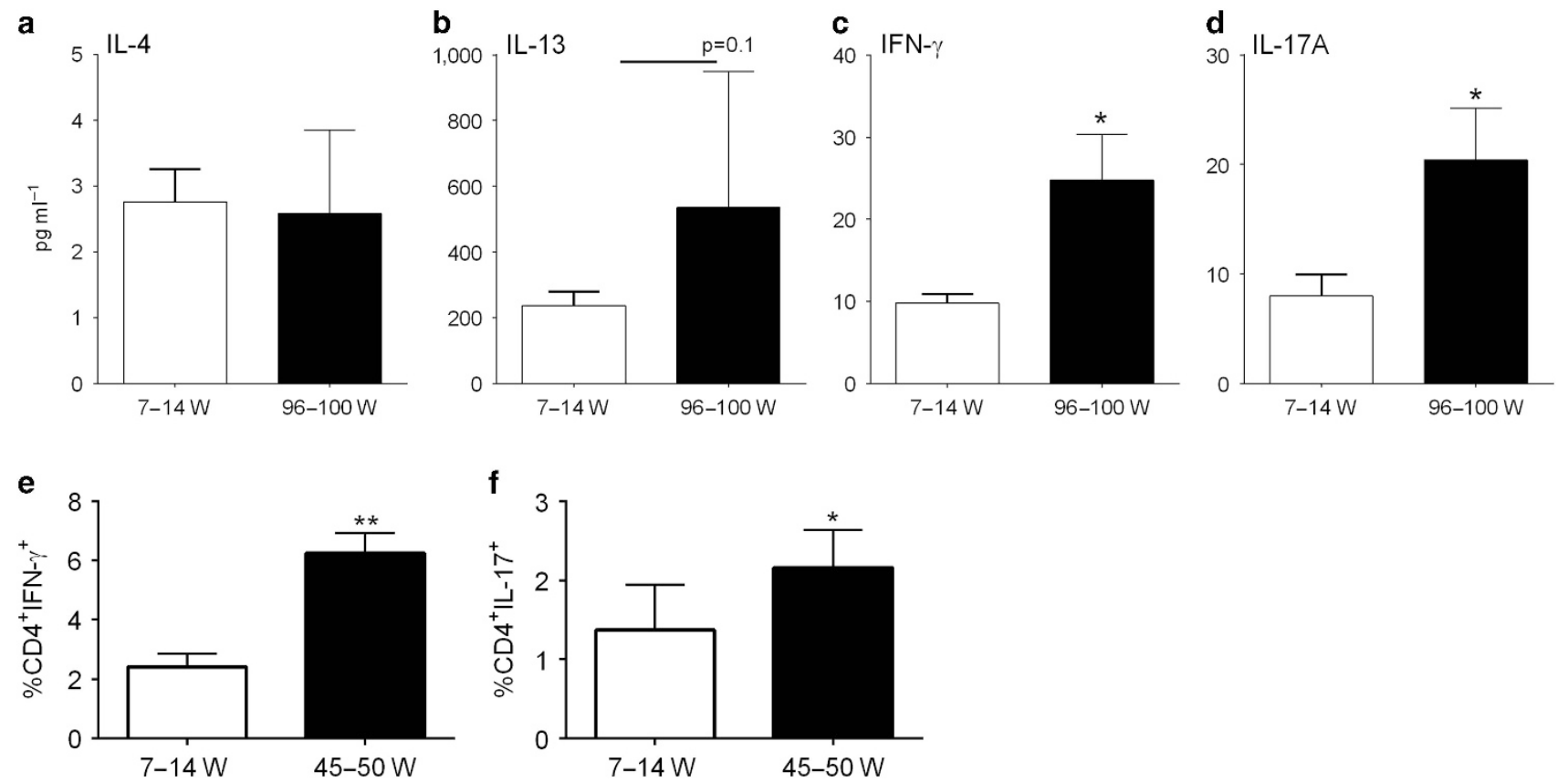

Figure 3 Increase in production of cytokines in the serum and lymphoid tissue of aged mice. (a-d) The concentrations of (a) interleukin (IL)-4, (b) IL-13, (c) interferon- $\gamma(\mathrm{IFN}-\gamma)$, and (d) IL-17A were measured in the blood serum of mice at 7-14 and 96-100 weeks by Luminex assay. Serum was collected from five mice per group. (e, f) The percentage of (e) CD4 ${ }^{+} \mathrm{IFN}-\gamma^{+}$cells and (f) $\mathrm{CD} 4^{+} \mathrm{IL}-17^{+}$cells in the spleens of mice at 7-14 and 45-50 weeks was determined by flow cytometry. Bar graphs show means $\pm \mathrm{s}$.d. of six to eight animals. Parametric $t$-test statistical tests were used to make comparisons between age groups. ${ }^{*} P<0.05,{ }^{* \star} P<0.01$ for comparison between age groups. W, week.

Figure 2 Aged male NOD.B10.H2 ${ }^{\mathrm{b}}$ mice have dacryoadenitis. (a) Representative pictures of the lacrimal gland (LGs) of mice at 7-14, 45-50, and 96-100 weeks of hematoxylin and eosin (H\&E)-stained sections of LG (left) with picture of total LG (right). Inflammation scores of the representative images appear in the lower left inset. (b) Representative images of the LGs of mice at 8, 41, and 96 weeks of H\&E-stained sections of LG of C57BL/6 mice. Inflammation scores of the representative images appear in the lower left inset. (c) Inflammation scores of LG pathology of NOD.B10. $2^{b}{ }^{b}$ mice. ${ }^{\#} P<0.05$, $\# \# P<0.001$ for comparison between NOD.B10.H2 ${ }^{\mathrm{b}}$ age groups. ${ }^{\dagger} P<0.05,{ }^{\dagger} P<0.01$ for comparison between C57BL/6 age groups. Two-way analysis of variance (ANOVA) followed by Holm-Sidak comparison test was used to make comparisons of inflammation scores. (d) Calculation of the foci area as a percentage of the total LG area. ${ }^{\#} P<0.05$, ${ }^{\# \# \#} P<0.001$ for comparison between NOD.B10.H2 ${ }^{\mathrm{b}}$ age groups. ${ }^{\dagger} P<0.05$, ${ }^{\dagger \dagger} P<0.01$ for comparison between C57BL/6 age groups. Two-way ANOVA followed by Holm-Sidak comparison test was used to make comparisons of inflammation scores. The data in $\mathbf{c}$ and $\mathbf{d}$ are the mean of at least five (range five to nine) LGs from different animals. (e) Tear volumes were measured by phenol red threads tests. Bar graphs show the means \pm s.d. of six to eight animals per group. (f) Tear epidermal growth factor (EGF) concentrations from NOD.B10. $2_{2}{ }^{b}$ mice were measured by enzyme-linked immunosorbent assay. Tear washings from both right and left eyes from one mouse per group were collected and pooled into a single tube, yielding a final sample of 12 individual samples per group divided into 3 independent experiments with 4 samples per experiment. (g) Relative fold expression changes of interferon- $\gamma$ (IFN- $\gamma$ ), interleukin (IL)-17A, IL-13, IL-1 $\beta$, and tumor necrosis factor- $\alpha$ (TNF- $\alpha$ ) mRNA in the LG. Bar graphs show means \pm s.e.m. of six samples per age (the experiment was repeated twice with similar results).

(h) Representative images of frozen lacrimal gland sections immunostained for CD4 (upper), CD8 (middle), and B220 (bottom) of mice at 7-14 weeks compared with mice at 96-100 weeks. As a negative control, LG section of 96-100-week group was stained without primary antibody (upper right). Insets are original magnification $\times 4$ and larger images are original magnification $\times 20$ in the 96-100-week group. (i) Flow cytometric analysis of LG at 7-14, 45-50 and 96-100 weeks. Right and left extraorbital LGs from one mouse per group were excised and pooled into a single tube, yielding a final sample of 12 individual LG samples per group and age divided into 3 independent experiments with 4 samples per experiment. Bar graphs show means \pm s.d. Parametric $t$-test statistical tests were used to make comparisons between age groups. ${ }^{\star} P<0.05,{ }^{* \star} P<0.01,{ }^{\star \star \star} P<0.001,{ }^{\star \star \star *}{ }^{*} P<0.001$ for comparison between age groups. W, week. 
a
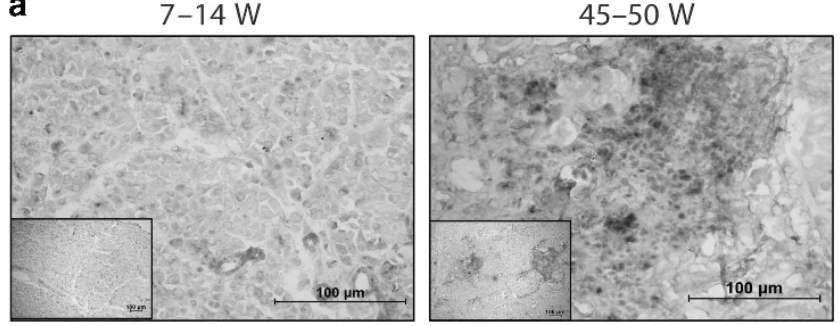

96-100 W

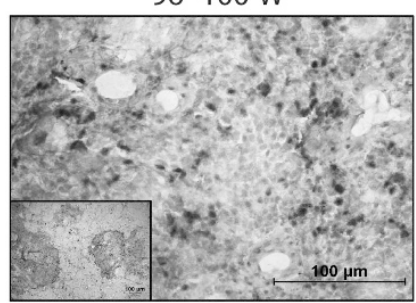

b

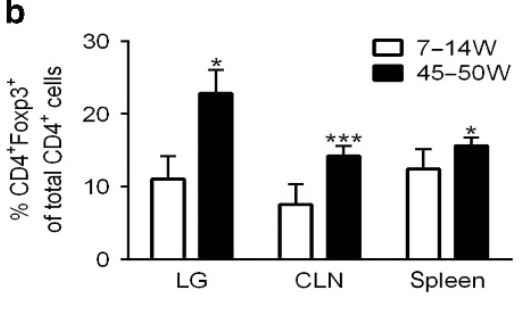

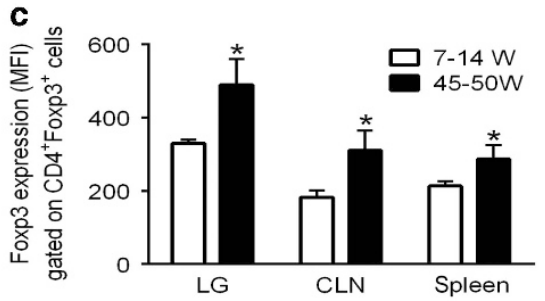

d

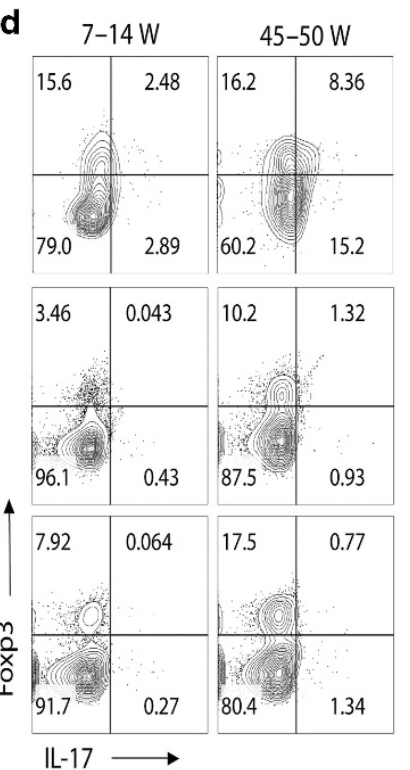

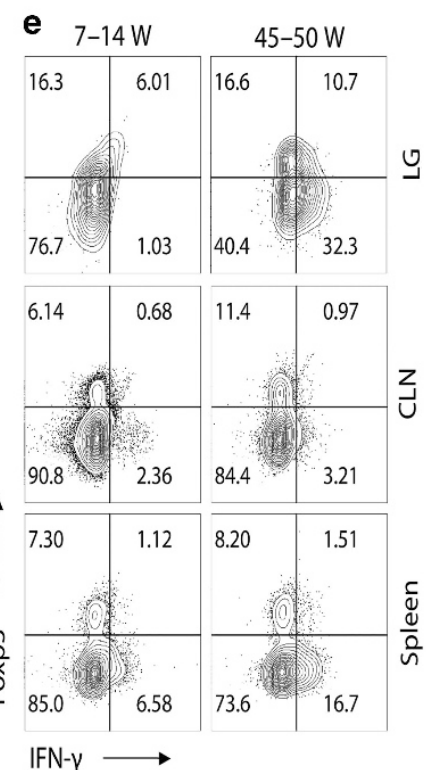

f FMO controls

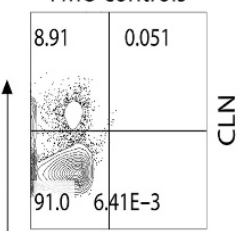

No IL-17

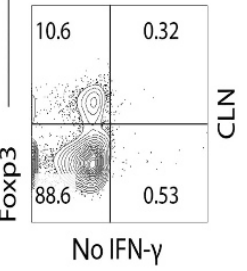

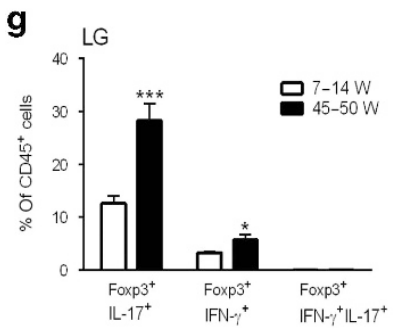
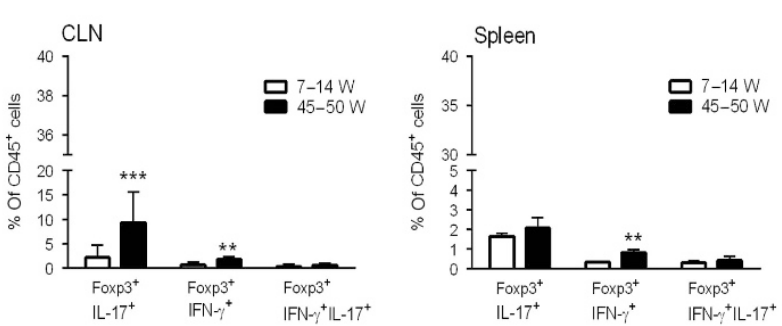

Figure 4 Aged NOD.B10. $2^{\mathrm{b}}$ mice have an increase in $\mathrm{CD} 4^{+}{ }^{\mathrm{Foxp}}{ }^{+}$T regulatory cells (Tregs) that produce interleukin-17 (IL-17) and interferon- $\gamma$ (IFN- $\gamma$ ). (a) Immunohistochemical staining for Foxp3 (forkhead box P3) in the lacrimal gland (LG) demonstrated an increase in Foxp3 with increasing age. Original magnification is $\times 20$; inset is $\times 4$. (b) Flow cytometric analysis showing the percentage of CD4 ${ }^{+}$Foxp3 ${ }^{+}$in LG, submandibular gland (SMG), cervical lymph node (CLN), and spleen of mice at 7-14 and 45-50 weeks. Lymphocytes were individually identified on the basis of forward scatter and side scatter properties, subsequently gated on the basis of forward scatter height vs. forward scatter area (singlets 1 ), and then gated on side scatter height vs. side scatter area (singlets 2). Propidium iodide exclusion was used to discriminate live cells; CD4 ${ }^{+}$T cells were gated based on FSC-A properties. (c) Mean fluorescence intensity (MFI) of Foxp3 (MFI) in the LG, CLN, and spleen of mice at 7-14 and 45-50 weeks. (d, e) Flow cytometric analysis of LG, SMG, CLN, and spleen indicated an increase in (d) Foxp3 ${ }^{+}$IL-17A ${ }^{+}$cells or (e) Foxp3 ${ }^{+}$IFN- $\gamma^{+}$cells in mice at 45-50 weeks.

Representative plots are shown for each age group. (f) Fluorescence minus one (FMO) controls are shown in the right. (g) Bar graphs show cumulative data presented in $\mathbf{d}$ and $\mathbf{e}$. Graphs $(\mathbf{b}-\mathbf{e}, \mathbf{g})$ show the means \pm s.d. of four to six samples per age (the experiment was repeated three times with similar results). W, week. ${ }^{\star} P<0.05,{ }^{\star \star} P<0.01,{ }^{\star \star \star} P<0.001$ for comparison between age groups. 
expression while acquiring the ability to produce IL-17 and IFN- $\gamma$. In addition, these data show an increase in $\mathrm{CD} 4{ }^{+}$IFN- $\gamma^{+}$(Foxp3-negative) and CD4 ${ }^{+} \mathrm{IL}-17^{+}$(Foxp3negative) cells, suggesting the loss of suppressive ability of Tregs with age (Figure 4d,e). No significant increase was observed in Foxp $3^{+}$IL- $17^{+}$IFN- $\gamma^{+}$cells with age in any tissue (Figure 4g). To demonstrate our gating strategy for these experiments, the fluorescence minus one (Figure 4f) and no stimulation control plots (Supplementary Figure S2a) are presented.

We then examined the gene expression of this cell population for inflammatory or suppressive cytokine genes, markers of Tregs, and markers for $\mathrm{CD}^{+}{ }^{+}$Foxp $3^{+} \mathrm{IL}-17^{+}$ cells. To accomplish this, $\mathrm{CD} 4{ }^{+} \mathrm{CD} 25^{-}$(T responders (Tresps)) and $\mathrm{CD} 4{ }^{+} \mathrm{CD} 25^{+}$(Tregs) cells were isolated from the spleens and CLNs of NOD.B10.H2 $2^{\mathrm{b}}$ mice at 7-14 (young) or 45-50 weeks (old) by magnetic bead separation (Supplementary Figure S2b). A significant increase of IFN- $\gamma$, IL-4, and IL-10 was seen in old Tresps compared with young Tresps (Figure 5a). This indicates that old Tresps have greater cytokine production than young Tresps and suggests a general uncontrolled phenotype of these cells. A significant increase for IL-17A and IL-10 was observed in old Tregs in agreement with the increase of IL- $17^{+}$cells seen in Figure 5a. A change in the expression of IFN- $\gamma$ between young and old Tregs was not observed and this may be due to a limitation of the isolation as the cells were pooled from both the CLN and spleen to obtain enough cells. TGF- $\beta 1$ and 2 and TNF- $\alpha$ gene expression did not change (data not shown). It has been reported in the literature that Treg conversion to effector cells is accompanied by increased expression of CCR6, a chemokine receptor expressed by Th17 cells. ${ }^{36,37}$ Accordingly, we examined the expression of CCR6 and ROR $\gamma$ t, the transcription factor of IL-17-producing cells, and observed an increase in these markers in both old Tresps and Tregs, indicating an increase in IL-17-producing cells. Interestingly, Foxp3 expression increased in Treps and was unchanged in old Tregs. The small increase in Foxp3 expression in Tresps may be due to a contaminating population of Foxp $3^{+}$cells that remained after cell isolation. This occurred concurrently with increased production of IL-17A. This is consistent with previous studies demonstrating the phenotype of IL- $17^{+}$Foxp $3^{+}$and the expression of ICOS increased in old Tregs; however, these cells maintain suppressive ability. ${ }^{27}$ The expression of CTLA-4 decreased in old Tregs, suggesting less suppressive ability. GITR gene expression did not significantly change with age (data not shown). Overall, these results suggest that with age, mice spontaneously acquire an inflammatory IL- $17^{+}$Foxp $^{+}$or IFN- $\gamma^{+}$Foxp $3^{+}$phenotype.

\section{$\mathrm{CD}^{+}{ }^{+} \mathrm{CD} 25^{+}$Tregs are dysfunctional in aged NOD.B10.H2 mice}

With an increase in $\mathrm{CD} 4{ }^{+} \mathrm{CD} 25^{+}$cells, we sought to determine their suppressive ability in this model. Mixed lymphocyte assays were performed to assess the suppressive ability of Tregs in aged NOD.B10.H2 ${ }^{\mathrm{b}}$ mice. Again, $\mathrm{CD} 4{ }^{+} \mathrm{CD} 25^{-}$(Tresps) and $\mathrm{CD} 4{ }^{+} \mathrm{CD} 25^{+}$(Tregs) cells were isolated from NOD.B10.H2 ${ }^{\mathrm{b}}$ mice at 7-14 (young) or 45-50 weeks (old) mice. To determine the ability of Tresps and Tregs to proliferate, each cell type was incubated for $72 \mathrm{~h}$ in anti-CD3-coated plates and WST was added in the last $4 \mathrm{~h}$ of incubation. Only Tresps proliferated in response to anti-CD3 stimulation (Figure $4 \mathbf{b}$ ). To test suppressive ability, Tresps and Tregs were incubated in 1:1, 2:1, and 4:1 ratios (Tresps/Tregs) for $72 \mathrm{~h}$ in anti-CD3-coated plates. WST was added the last $4 \mathrm{~h}$. As seen in Figure 5c, young $\mathrm{CD} 4{ }^{+} \mathrm{CD} 25^{+}$Tregs effectively suppressed young Tresps. However, old $\mathrm{CD} 4{ }^{+} \mathrm{CD} 25^{+}$Tregs showed significantly less ability to suppress the proliferation of young Tresps. Similarly, young Tregs are able to suppress young Tresps significantly more than old Tresps, indicating an increase in proliferation of Tresps with aging (Figure 5c).

To examine the ability of Tregs to regulate cytokine production the concentration of IFN- $\gamma$ and IL-17A was measured in culture supernatant by Luminex assay. Importantly, the same pattern of suppression is observed with IFN- $\gamma$, as young Tregs are able to suppress IFN- $\gamma$ production by young Tresps and old Tresps by $50 \%$ and $40 \%$, respectively. In contrast, old Tregs were unable to suppress the production of IFN- $\gamma$ by either young or old Tresps (Figure 5d). Similarly, old Tregs were unable to suppress the production of IL-17 by either young or old Tresps. Interestingly, co-cultures with old Tregs with young Tresps had an eightfold increase of IL-17A compared with young Tresps alone and an even greater increase than co-cultures containing young Tregs: young Tresps. Old Tregs/old Tresps co-cultures had a threefold increase in IL-17A compared with old Tresps alone (Figure 5e).

\section{Aged dysfunctional Tregs are potentially pathogenic}

In order to determine whether Tregs from 45-50-week-old mice mediate disease, adoptive transfer studies were performed. Tregs $\left(\mathrm{CD} 4{ }^{+} \mathrm{CD} 25^{+}\right)$or Tresps $\left(\mathrm{CD} 4{ }^{+} \mathrm{CD} 25^{-}\right)$were isolated from the spleens and CLNs of mice at 7-14 and 45-50 weeks as stated above (see Supplementary Figure S2b for an example). Young (8 weeks old) $\mathrm{T}$ cell-deficient RAG1KO mice were intraperitoneally injected with $2 \times 10^{6}$ Tregs or Tresps cells. Disease parameters were measured after 5 weeks. LGs of recipient mice that received aged Tregs or Tresps cells had a significant increase in periductal infiltration of $\mathrm{CD} 4{ }^{+} \mathrm{T}$ cells (Figure 6a). $\mathrm{CD}^{+}{ }^{+} \mathrm{T}$-cell infiltration was quantified by flow cytometry and indicated a significant increase in $\mathrm{CD} 4^{+} \mathrm{T}$ cells, more specifically $\mathrm{CD} 4{ }^{+} \mathrm{IFN}-\gamma^{+}$cells, compared with recipients that received Tregs or Tresps cells from mice at 7-14 weeks (Figure $6 \mathbf{b}$ ). Infiltration into the LG did not change when comparing Tregs and Tresps in old mice, demonstrating that old Tregs and Tresps both infiltrate the LG and produce similar levels of IFN- $\gamma$. Examination of goblet cell (GC) density in the conjunctiva indicated that neither young Tregs nor Tresps mediate GC loss in recipient mice. However, Tregs and Tresps from aged mice significantly reduced GC density compared with mice that received young Tregs or Tresps (Figure 6c). Tregs and Tresps from aged mice mediate GC loss at similar levels. To quantify LG pathology, inflammation scores were assigned to LG sections and the size of the foci area 

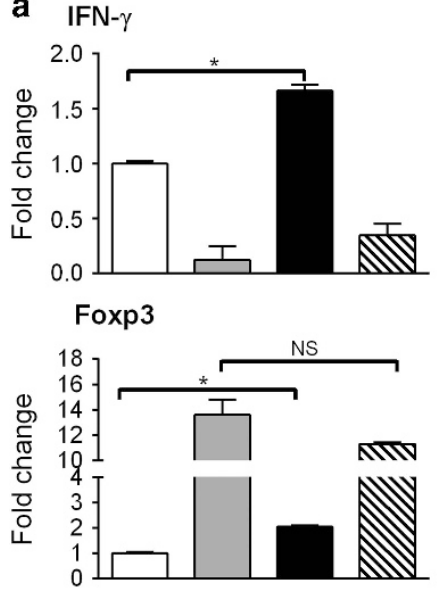

ICOS

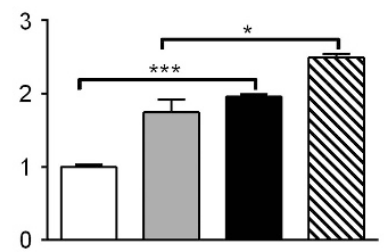

b

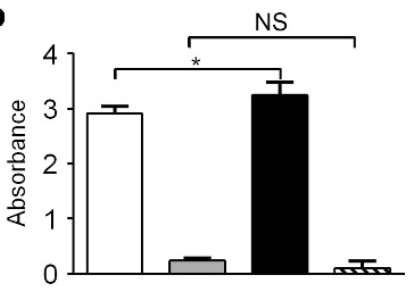

C

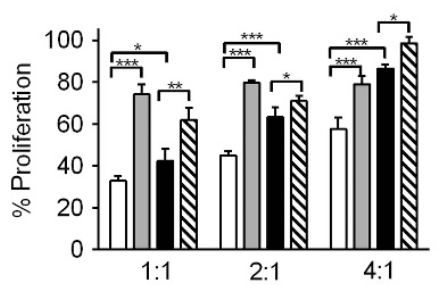

$\square$ Young Tresps: young Tregs Old Tresps: young Tregs
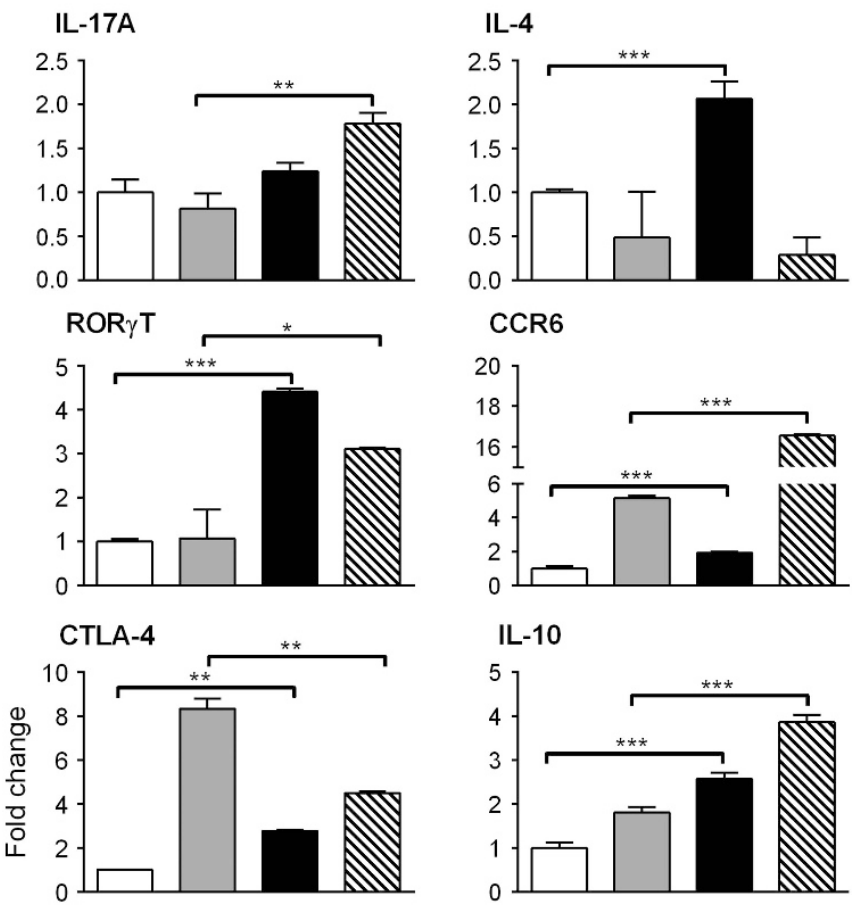

IL-10

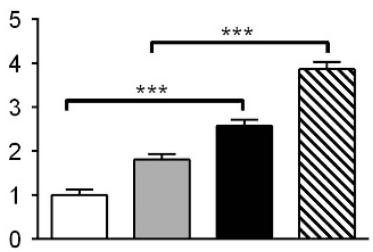

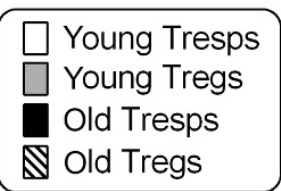

d
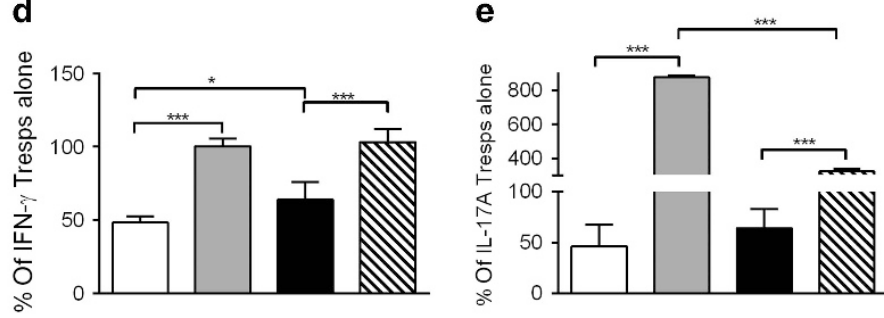

Figure 5 Aged mice develop $\mathrm{CD} 4{ }^{+} \mathrm{CD} 25^{+} \mathrm{Foxp} 3^{+} \mathrm{IL}-17^{+}$or $\mathrm{CD} 4^{+} \mathrm{Foxp} 3^{+} \mathrm{IFN}-\gamma^{+}$cells that have an effector cell phenotype and are dysfunctional. (a) Relative fold expression changes in T effector and T regulatory cell (Treg) marker mRNA of young Tresps (CD4 ${ }^{+}$CD25 ), young Tregs $\left(\mathrm{CD} 4{ }^{+} \mathrm{CD} 25^{+}\right)$, old Tresps, and old Tregs. Tresp, T responders. Fold change was determined by comparison to young Tresp cells. Bar graphs show means + s.d. of four to six samples per group. (b) Cell proliferation was measured for young CD4 ${ }^{+} \mathrm{CD}_{25} 5^{-}$Tresps, young CD4 ${ }^{+}$CD25 ${ }^{+}$Tregs, old $\mathrm{CD} 4{ }^{+}$CD25- Tresps, and old CD4 ${ }^{+}$CD25 ${ }^{+}$Tregs with colorimetric cell proliferation WST-1 reagent. (c) Cell proliferation was measured in co-cultures of Tregs and effector T-cell responders (CD4 ${ }^{+}$CD25; Tresps) from young (7-14 weeks) and old (45-50 weeks) mice. Tregs and Tresps were cultured in 1:1, 2:1, or $4: 1$ ratios (Tresps/Tregs) for $72 \mathrm{~h}$. The \% proliferation was determined by calculating proliferation compared with Tresps without Tregs. Bar graphs show means \pm s.d. of the average of three independent experiments. (d) The production of interferon- $\gamma$ (IFN- $\gamma$ ) was determined by Luminex assay. Co-culture supernatants were collected in triplicate and the percentage of IFN- $\gamma$ compared with Tresps alone was determined. Bar graphs show a representative experiment of three independent experiments with the same trend. (e) The production of interleukin-17A (IL-17A) was determined by Luminex assay. Co-culture supernatants were collected in triplicate and the percentage of IL-17A compared with Tresps alone was determined. Bar graphs show a representative experiment of three independent experiments with the same trend. Parametric $t$-test statistical tests were used to make comparisons between age groups. ${ }^{\star} P<0.05,{ }^{* *} P<0.01,{ }^{* \star *} P<0.001$ for comparison between age groups. NS, nonsignificant; W, week.

as a percentage of the total glandular area was calculated, as in Figure 2. Adoptive transfer of old Tregs or Tresps yielded increased LG inflammation scores compared with transfer of young Tregs or Tresps (Figure 6d). Similarly, the percentage of total area with T-cell infiltration increased in recipients that received young Tregs or Tresps (Figure 6e). These results 

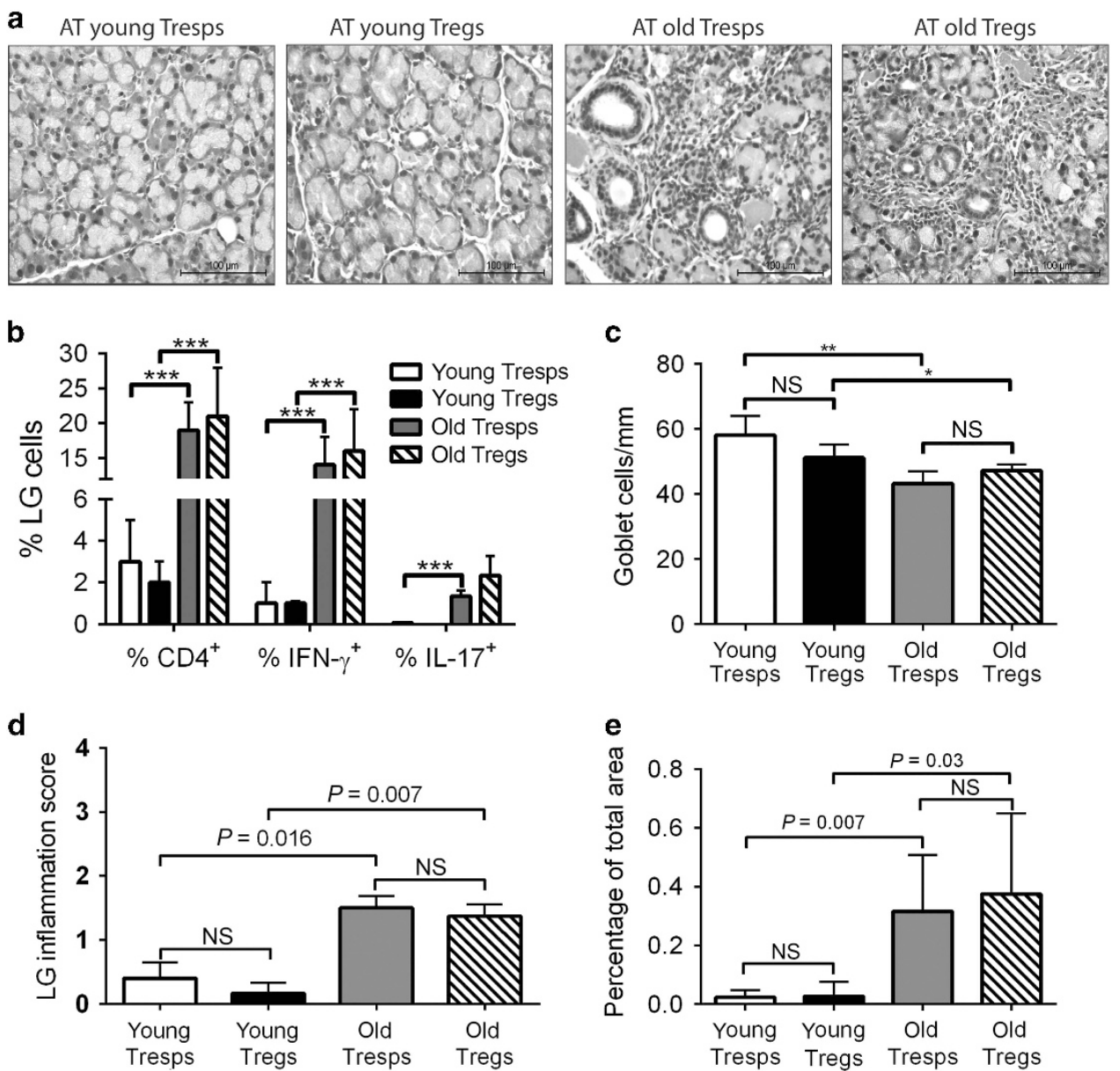

Figure 6 Adoptive transfer (AT) of aged T regulatory cell (Tregs) mediates disease in recipient animals. (a) Hematoxylin and eosin (H\&E) staining of lacrimal glands (LGs) of AT recipients indicated CD4 ${ }^{+}$T-cell infiltration in recipients receiving old T responders (Tresps) or Tregs. Representative images $(\times 40)$ are shown for each AT group. (b) Flow cytometric analysis of recipient LGs indicated an increase in CD4 ${ }^{+} \mathrm{T}_{\text {cells, specifically CD4 }}{ }^{+}$IFN- $\gamma^{+}$and $\mathrm{CD} 4^{+} \mathrm{IL}-17^{+}$cells, in mice receiving Tresps or Tregs from mice at $45-50$ weeks. Bar graphs show means \pm s.d. of four to six samples per AT group. (c) Number of PAS ${ }^{+}$conjunctival goblet cells counted in paraffin-embedded sections expressed as number per mm. Bar graphs show means $\pm \mathrm{s}$.d. of four to six animals per AT group. Parametric $t$-test statistical tests were used to make comparisons between age groups. ${ }^{*} P<0.05,{ }^{* \star} P<0.01,{ }^{* * *} P<0.001$. (d) Inflammation scores of LG pathology of AT recipients. Nonparametric Mann-Whitney $U$ statistical tests were used to make comparisons of inflammation scores. (e) Calculation of the foci area as a percentage of the total lacrimal gland area. Nonparametric Mann-Whitney $U$ statistical tests were used to make comparisons of inflammation scores. The data in $\mathbf{c}$ and $\mathbf{d}$ are the mean of four to six LGs from different animals. NS, nonsignificant; PAS, periodic acid-Schiff; W, week.

indicate that Tregs from aged mice lose suppressive ability and may possibly participate in mediating SS-like disease.

\section{DISCUSSION}

Aging is a risk factor for development of DED, SS, and many other autoimmune diseases. Although the pathological changes that occur with age have been described in both humans and animal models, the mechanisms of this process are poorly understood. There is increasing evidence that the ocular surface epithelial disease that develops in DED and SS is the result of inflammation. ${ }^{16,33}$ These changes are accompanied by and may be worsened by decreased LG secretion and conjunctival goblet cell density or increased tear evaporation because of lipid tear deficiency. In both humans and animals models, DED and SS are mediated by $\mathrm{CD} 4^{+} \mathrm{T}$ cells that predominately produce IFN- $\gamma$ and IL-17A. ${ }^{16,34,38,39}$ Although the autoantigen(s) have not been definitively described, the immune response depends on resident ocular surface dendritic cells that are activated in response to dry eye or SS autoantigens and present antigens to lymphocytes in regional draining lymph nodes. ${ }^{40}$ The most prevalent risk factors are age and sex, ${ }^{7}$ and hence we hypothesized that changes in the immune response would occur with age and these changes would be translated to the ocular surface. To test this hypothesis, we examined the immunological changes that occur with age at the ocular surface, LG, and regional draining lymph nodes of male NOD.B10- $\mathrm{H} 2^{\mathrm{b}}$ mice, as male NOD mice develop dacryoadenitis, whereas females will have sialodenitis. ${ }^{41}$ However, NOD.B10-H2 ${ }^{\mathrm{b}}$ do not develop type 1 diabetes. ${ }^{32,42}$ Our previous published studies ${ }^{13}$ and Figure 2 show that $\mathrm{C} 57 \mathrm{BL} / 6$ mice have the same disease phenotype that naturally occurs with age, but NOD.B10.H2 $2^{\mathrm{b}}$ develop disease sooner, making this a useful model for aging studies. 
Our results indicated that aging induced the phenotype of DED, characterized by increased corneal barrier disruption, decreased density of conjunctival GCs, and an increase in $\mathrm{CD}^{+}{ }^{+} \mathrm{T}$-cell infiltration in the conjunctiva. This was also accompanied by increased expression of IFN- $\gamma$, IL-17A, and MHC class II transcripts in the conjunctiva. Previous studies have shown that IFN- $\gamma$ induces goblet cell apoptosis via endoplasmic reticulum stress and cornification of conjunctival epithelial cells. ${ }^{34,38,39,43-45}$ IL-17A increases the activity of matrix metalloproteinases that induce corneal permeability. ${ }^{16,19}$ This occurred with both the mice at $45-50$ and the 96-100 weeks. These results were similar to those observed in our previous study that examined aging in the $\mathrm{C} 57 \mathrm{BL} / 6$ mouse strain and implies a generalized aging phenotype that is not inbreed strain specific. ${ }^{13}$

In the LG, we observed gross atrophy of the LG, lymphocytic infiltration, and loss of acinar cells that progressed with aging. To examine LG gland function, epidermal growth factor and tear volume were examined. In spite of LG pathology, old mice had an increase in epidermal growth factor concentration in tears and also tear volume. Age-induced changes in tear parameters (such as decreased tear volume, tear meniscus height, and tear flow) are often found in the aged population. ${ }^{46-48}$ In various animal models, mixed results have been observed, with an increase, decrease, or no change in tear volume. ${ }^{13,49-51}$ The overall tear volume is the composite of fluid secretion by the LG, ocular surface epithelium, and conjunctival goblet cells. An increase in tear volume can be due to leakage of conjunctival blood vessels during ocular surface inflammation. We did not record body weights of aging mice and it is possible that tear volume would decrease if tear volumes are normalized by body weight. We recently reported that in another SS model, the C57BL/6.NOD-Aec1Aec2 mice have increased tear volume with aging. Moreover, the ratio of IgA (produced by LG) and IgG and IgM (plasma immunoglobulins) in tears did not increase with aging from 4 to 20 weeks, whereas an increase of $\operatorname{IgA} / \operatorname{IgG}$ and IgA/IgM was noted in wild-type mice, indicating reduced IgA secretion in the autoimmune strain. ${ }^{52}$ Similarly, increased tear volume was also observed in the Spdef null mouse that lacks conjunctival goblet cells but has an inflammatory cell infiltration..$^{50}$

The expression of inflammatory cytokines, IFN- $\gamma$, IL-17A, IL-1 $\beta$, and TNF- $\alpha$, significantly increased with age within the LG. In agreement with this, an increase in $\mathrm{CD} 4{ }^{+} \mathrm{T}$ cells and $\mathrm{CD}^{+} \mathrm{T}$ cells and $\mathrm{B}$ cells was observed in the LG by immunohistochemistry and flow cytometry. In humans, lymphocyte infiltration has been detected and increases with age in individuals over 40 years of age. ${ }^{53}$ Increased lymphocytes and inflammatory cytokines lead to a chronic fibrotic inflammatory disease of the LG. ${ }^{11,54}$

We next asked whether this disease was limited to the LG and ocular surface or was systemic with age. The presence of inflammatory cytokines in serum and an increase of $\mathrm{CD} 4^{+}$ IFN- $\gamma^{+}$cells and $\mathrm{CD} 4^{+} \mathrm{IL}-17^{+}$cells in the spleen with age indicate a systemic autoimmune response that can be manifested at the ocular surface and LG. With this, we examined the numbers of $\mathrm{CD} 4{ }^{+} \mathrm{CD} 25^{+}$Foxp $3^{+}$Tregs in the LG, CLN, and spleen. In spite of increased autoimmune disease, there was a significant increase in the frequency of these cells in the LG, CLN, and spleen with age. The effect of aging on Tregs is not understood and conflicting results have been reported. ${ }^{55} \mathrm{It}$ has been reported that Tregs increase the spleen and lymph nodes in mice and this was correlated with decreased protection from pathogens. ${ }^{56-58}$ There are reports that increased infiltration of Foxp $3^{+}$cells is positively correlated with increased lymphocyte infiltration and increase disease severity in the lacrimal and salivary gland of SS patients. ${ }^{59,60}$ Overall, there is ample evidence to suggest that $\mathrm{CD} 4{ }^{+}$Tregs increase with age, ${ }^{61}$ although why these cells increase with age or what induces the accumulation is not understood.

This led us to examine the function of Tregs in aged animals with ocular surface disease. Others have reported that Tregs lose suppressive ability with age influencing autoimmunity. ${ }^{23,24,55}$ Our results indicate that $\mathrm{CD} 4{ }^{+} \mathrm{CD} 25^{+} \mathrm{T}$ cells maintain Foxp3 expression but lose suppressive ability with age. There are reports of Tregs becoming "pathogenic exTregs" that lose Foxp3 expression and gain the phenotype of Th17 cells. ${ }^{20}$ Other studies suggest that Tregs can maintain Foxp3 expression while acquiring the ability to produce small amounts of inflammatory cytokines. However, these cells maintain suppressive ability. ${ }^{15}$ It is important to note that the change in Treg function in our studies occurred spontaneously with increased age. In addition to losing suppressive ability, Foxp $3^{+}$cells in our model acquired the ability to produce significant amounts of IFN- $\gamma$ and IL-17. Paradoxically, Foxp $3^{+}$cells produce similar levels of IFN- $\gamma$ as $\mathrm{CD} 4{ }^{+} \mathrm{CD} 25^{-}$cells. Interestingly, $\mathrm{CD} 4{ }^{+} \mathrm{CD} 25^{+}$Tregs have significantly increased production of IL-17 compared with $\mathrm{CD} 4{ }^{+} \mathrm{CD} 25^{-}$cells. This suggests that these cells acquire a greater ability to produce inflammatory cytokines in LG and LG-draining CLN with age and this occurs to a greater extent here than it does in the spleen.

Our adoptive transfer studies suggest that aged Tregs, in addition to loss of suppressive ability, mediate disease through production of inflammatory cytokines while maintaining Foxp3 expression. These results suggest that old Tregs may become pathogenic themselves. However, it is not possible to obtain an extremely pure cell population of Tregs to perform adoptive transfer experiments. Thus, we undoubtedly transferred some CD4 ${ }^{+}$Foxp3-negative cells (Tresps) in the Treg fraction. It is possible that old Tregs do not suppress overactive Tresps present in the cell fraction that expand and mediate disease. Because of this, it is inherently difficult to conclude that old Tregs are themselves pathogenic and can independently mediate disease. It is also possible that conversion of Tregs to Tresps occurs because of the influence of the lymphopenic environment. However, this only occurs in the old Treg group, as with transfer of young Tregs there was very little infiltration or glandular inflammation, suggesting that dysfunction of Tregs occurs with age. Overall, our results suggest that dysregulation and acquisition of an effector cell phenotype of Tregs could to be a major mechanism for increased incidence of DED and SS with age. Whether the change in phenotype is a 
consequence of inflammation or the cause of inflammation is still unknown.

There are several other reports of Foxp $3^{+} \mathrm{IL}-17^{+}$or Foxp $3^{+}$IFN- $\gamma^{+}$cells. $^{37,62,63}$ However, in these models, Foxp $3^{+}$cells maintain suppressive ability. To the best of our knowledge, this the first report of a population of Tregs that express Foxp 3 and are potentially pathogenic in nature. Thus, this may be an undiscovered Foxp $3^{+}$cell population that occurs in mucosal tissues with age. Our results suggest that this mechanism may contribute to the pathogenesis observed in patients with SS. The major strength of this work is the spontaneous nature (with age) in which Tregs, while maintaining Foxp3 expression, produce IL-17 and IFN- $\gamma$ and may contribute to pathology.

\section{METHODS}

Mice. NOD.B10-H2 ${ }^{\mathrm{b}}$ mice were purchased from The Jackson Laboratory (Bar Harbor, ME) for establishment of mouse colonies in our vivarium. Male mice from 7 to 100 weeks of age were used. All animal experiments were approved by the institutional animal care and use committee at Baylor College of Medicine and adhered to the Association for Research in Vision and Ophthalmology Statement for the Use of Animals in Ophthalmic and Vision Research. At least 32 animals were used per age group: 5 for histology; 6-8 for real-time PCR, 8-10 for flow cytometry, 8-10 for tear collection, and 6-8 for in vitro Treg assay. All old mice were visually examined for tumors before use.

Measurement of corneal permeability. Corneal epithelial permeability to OGD (70,000 molecular weight; Invitrogen, Eugene, OR) was assessed by instilling $0.5 \mu \mathrm{l}$ of OGD onto the ocular surface $1 \mathrm{~min}$ before killing, as previously described. ${ }^{16}$ Corneas were rinsed with phosphate-buffered saline and photographed under fluorescence excitation at $470 \mathrm{~nm}$. The severity of corneal OGD staining was graded in digital images in the $2 \mathrm{~mm}$ central zone of each cornea by two masked observers, using the NIS Elements software (Nikon, Melville, $\mathrm{NY}$ ). Four to six mice (8-12 eyes) per each group were examined in two different sets of experiments.

Tear washings and epidermal growth factor enzyme-linked immunosorbent assay. Tear fluid washings were collected from 12 animals/group/age (7-14, 45-50, and 96-100 weeks) in two independent experiments using a previously reported method. ${ }^{64}$ One sample consisted of tear washings from both eyes of one mouse pooled $(2 \mu \mathrm{l})$ in phosphate-buffered saline $+0.1 \%$ bovine serum albumin $(8 \mu \mathrm{l})$ and stored at $-80^{\circ} \mathrm{C}$ until the assay was performed. Results are presented as means \pm s.d. $\left(\mathrm{pg} \mathrm{ml}^{-1}\right)$.

Tear volume measurements. Phenol red threads were used to measure tear volume, as previously described. ${ }^{65}$ Briefly, a phenol red impregnated thread (Zone-Quick; Showa Yakuhin Kako, Tokyo, Japan) was held in the lateral canthus of each eye for $20 \mathrm{~s}$. A color change from yellow to red occurs in the thread when tears are absorbed. The distance wet by tears was converted to volume according to a previously published standard. ${ }^{65}$

Histology, periodic acid-Schiff staining, and immunohistochemistry. Five extraorbital LGs and eyes from each group (7-14, 45-50, and $96-100$ weeks) were surgically excised, fixed in $10 \%$ formalin, embedded in paraffin, and $8 \mu \mathrm{m}$ sections were cut. Sections were stained with hematoxylin and eosin for evaluating morphology and with periodic acid-Schiff reagent for measuring GC density, and images were acquired and processed as previously published. ${ }^{35}$

For immunohistochemistry, five extraorbital LGs and eyes from each group (7-14, 45-50, and 96-100 weeks) were embedded in optimal cutting temperature compound (VWR, Suwanee, GA) and flash frozen in liquid nitrogen. Sagittal $8 \mu \mathrm{m}$ sections were cut with a cryostat (HM 500; Micron, Waldorf, Germany) and placed on glass slides that were stored at $-80^{\circ} \mathrm{C}$. Immunohistochemistry was performed to detect cells in the conjunctiva and LGs stained positively for CD4 (clone H129.9; $10 \mu \mathrm{g} \mathrm{ml}^{-1}$ ), CD8 (clone 53-6.2, $10 \mu \mathrm{g} \mathrm{ml}^{-1}$ ), B220 (clone 30F11, $20 \mathrm{\mu g} \mathrm{ml}^{-1}$ ) (BD Bioscience, San Diego, CA) and Foxp3 (clone FJK-16 S, $20 \mu \mathrm{g} \mathrm{ml}^{-1}$ ) (eBioscience, San Diego, CA). $\mathrm{CD}^{+}{ }^{+} \mathrm{T}$ cell infiltration and GC density was determined by counting cells in three section (at least $100 \mu \mathrm{m}$ apart) from six different animals of each strain and at each time point. Positively stained cells were counted in the GC-rich area of the conjunctiva over a length of at least $500 \mu \mathrm{m}$ in the epithelium and to a depth of $75 \mu \mathrm{m}$ below the epithelial basement membrane in the stroma, for a distance of at least $500 \mu \mathrm{m}$ (NIS Elements software).

RNA isolation and real-time PCR. Total RNA from conjunctiva or the corneal epithelium was extracted using a QIAGEN RNeasy Plus Micro RNA isolation kit (Qiagen, Hilden, Germany) following the manufacturer's protocol. Conjunctiva or extraorbital LG was surgically excised. One sample equaled the tissue pooled from both eyes or both LGs of each animal. After isolation, the concentration of RNA was measured and cDNA was synthesized using the Ready-To-Go You-Prime First-Strand kit (GE Healthcare, Chicago, IL). Real-time PCR was performed using specific Taqman probes for IFN- $\gamma$ (Ifng) (Mm00801778_m1), IL-17A (Il17a) (Mm0043918_m1), IL-4 (Il4) (Mm00445259M_m1), IL-13 (Il13) (Mm99999190_m1), IL-10 (Il10) (Mm00439614_m1), TGF- $\beta 1$ (Tgfb1) (Mm00441724), TNF- $\alpha$ (Tnfa) (Mm99999068_m1), IL-1 $\beta$ (Il1b) (Mm00434228_m1 genes), ROR $\gamma \mathrm{T}$ (Rorc) (Mm00441139_m1), ICOS (Icos) (Mm00497600_m1), CCR6 (Ccr6) (Mm01700299_m1), Foxp3 (Foxp3) (Mm00475162_m1), GITR (Tnfrsf1) (Mm00437136_m1), CTLA-4 (Ctla4) (Mm00486849) (Taqman Universal PCR Master Mix AmpErase UNG) in a commercial thermocycling system (StepOnePlus Real-Time PCR System, Applied Biosystems, Carlsbad, CA) according to the manufacturer's recommendations. The $\beta 2$ microglobulin (B2m) (Mm00437762_m1) gene was used as an endogenous reference for each reaction. The results of quantitative PCR were analyzed by the comparative $C_{t}$ method in which the target of change $=2^{-} \Delta \Delta^{\mathrm{Ct}}$ and were normalized by the $\mathrm{C}_{\mathrm{t}}$ value of $\beta 2$ microglobulin and the mean $C_{t}$ of relative mRNA level in the 7-14-week age group. Gene expression of 3-4 mice per strain per time point in two independent experiments with a total of 6-8 mice was determined.

LG inflammation scores and calculation of lymphocyte infiltration. Hematoxylin and eosin-stained LG sections were examined by light microscopy $(\times 10)$. Infiltration scores were assigned according to the following criteria of White and Casarett: ${ }^{66} 0$, indicated no foci of mononuclear cells was observed; 1 , indicated 1 to 5 foci (more than 20 cells per focus); 2 , indicated more than 5 foci were visible but without tissue damage; 3 , indicated more than 5 foci with moderate tissue damage; 4 , indicated extensive mononuclear infiltration with severe tissue destruction. Scores were assigned by two masked independent observers and averaged. The area of lymphocytic infiltration was circumscribed in digital images of hematoxylin and eosin-stained sections. The percentage infiltration was calculated as area of infiltration $\times 100 /$ total area using NIS Elements Software.

Flow cytometric analysis. Right and left extraorbital LGs from one mouse per age group were excised and pooled into a single sample from mice at 7-14, 45-50, or 96-100 weeks ( $n=12$ animals/group divided into three independent experiments with four samples per group/age/ experiment). Whole LGs were digested in collagenase type IV (Gibco, Waltham, MA, 17104-019) (0.1\% in Hank's balanced saline solution) for $1 \mathrm{~h}$ at $37^{\circ} \mathrm{C}$ in an orbital shaker. Single-cell suspensions of LGs containing $1 \times 10^{6}$ cells were prepared as previously described after collagenase digestion. ${ }^{13}$ Briefly, single-cell suspensions of collagenasedigested LGs were stained with anti-CD16/32, followed by cell surface staining as follows: anti-CD4-fluorescein isothiocyanate (FITC; 
GK1.5; BD Pharmingen, San Diego, CA), anti-CD8 $\alpha$-phosphatidylethanolamine (PE; clone 53-6.7; BD Pharmingen), or anti-CD $8 \alpha-\mathrm{PE}-$ Cy7 (BD Pharmingen 552877), anti-B220- allophycocyanin (APC) (clone RA3-6B2; BD Pharmingen), anti-CD161 (NK1.1)-BV650 (Biolegend, San Diego, CA, 108736), anti- $\gamma \delta$ TCR-BV510 (Biolegend, 118131), and anti- $\alpha \beta$ TCR-AF647 (ThermoFisher HM3621, Waltham, MA).

For CD4-FITC (BD Bioscience, clone GK1.5), CD25-PE (BD Pharmingen, clone PC61) and Foxp3-APC (eBioscience, clone FJK-16-S), single-cell preparations of splenocytes obtained from young mice were stained with the same antibodies and served as positive controls. The gating strategy used in this study was as follows: lymphocytes and monocytes were individually identified on the basis of forward scatter and side scatter properties, subsequently gated on the basis of forward scatter height vs. forward scatter area (singlets 1), then gated on side scatter height vs. side scatter area (singlets 2). Propidium iodide exclusion was used to discriminate live cells.

For intracellular cytokine staining, single-cell suspensions were obtained and $1 \times 10^{6}$ cells were incubated for $5 \mathrm{~h}$ with $1 \mu \mathrm{lml}{ }^{-1} \mathrm{Golgi}$ Stop (BD Bioscience), $1 \mu \mathrm{lml}{ }^{-1}$ Golgi Plug (BD Bioscience), phorbol 12-myristate 13-acetate $\left(1 \mu \mathrm{g} \mathrm{m}^{-1}\right)$ (Sigma, St Louis, MO), and ionomycin $\left(1 \mu \mathrm{g} \mathrm{ml}^{-1}\right)$ (Sigma) in $1 \mathrm{ml}$ in complete RPMI. Cells were stained with blue fluorescent reactive dye (Life Technologies, Grand Island, NY) for $30 \mathrm{~min}$ before incubation with Foxp3 Fixation/ Permeabilization working solution (eBioscience) for $18 \mathrm{~h}$. Cells were washed with $1 \times$ Permeabilization solution and incubated with antiCD16/32, followed by staining with anti-CD4-FITC (BD Bioscience, clone GK1.5), IL-17-PE (eBioscience, clone eBio17B7), anti-Foxp3APC (eBioscience, FJK-16S), anti-IFN- $\gamma$-PacificBlue (Biolegend, clone XMG1.2), and anti-CD45-AlexaFluor 700 (Biolegend, clone 30F11). The following gating strategy was used: dead cells were excluded by gating blue dye vs. CD $45+$ cells, subsequently gated on the basis of forward scatter height vs. forward scatter area (singlets 1), then gated on side scatter height vs. side scatter area (singlets 2). Cells were then gated on $\mathrm{CD}^{+}{ }^{+}$cells and Foxp $3^{+}$IFN $-\gamma^{+}$or Foxp $3^{+} \mathrm{IL}_{-17 \mathrm{~A}^{+}}$ cells were evaluated. A BD LSRII Benchtop cytometer was used for flow cytometry, and data were analyzed with BD Diva software version 6.7 (BD Pharmingen) and FlowJo software version 10 (Tree Star, Ashland, OR).

$\mathrm{CD}^{+}{ }^{+} \mathrm{CD}^{2} 5^{+}$regulatory T-cell isolation. $\mathrm{CD} 4{ }^{+} \mathrm{CD} 25^{+}$regulatory $\mathrm{T}$ cells were isolated via a two-step procedure in which $\mathrm{CD} 4^{+} \mathrm{T}$ cells were pre-enriched by depletion of unwanted cells. The $\mathrm{CD} 4^{+} \mathrm{T}$-cell fractions were incubated with anti-CD25-PE antibody and then magnetically labeled with microbeads and positively selected for $\mathrm{CD} 4{ }^{+} \mathrm{CD} 25^{+}$ $\mathrm{T}$ cells. This was performed according to the manufacturers' instructions with a $\mathrm{CD} 4{ }^{+} \mathrm{CD} 25^{+}$regulatory $\mathrm{T}$-cell isolation kit (Miltenyi Biotec, Auburn, CA; 130-091-041) on NOD.B10.H2 ${ }^{\mathrm{b}}$ mice at 7-14 or 45-50 weeks. These cells were used to perform regulatory T-cell assays or collection for quantitative gene expression. Purity of $\mathrm{CD} 4{ }^{+} \mathrm{CD} 25^{+}$isolation was confirmed by flow cytometry by CD4, CD25, and Foxp3 staining (Supplementary Figure S2b).

Regulatory T-cell assay. $\mathrm{CD} 4{ }^{+} \mathrm{CD} 25^{-}$cells (Tresps) and $\mathrm{CD} 4{ }^{+}$ $\mathrm{CD} 25^{+}$cells (Tregs) were isolated and co-cultured at Tresp/Treg ratios of $1: 1\left(1 \times 10^{5}: 1 \times 10^{5}\right.$ cells $), 2: 1\left(1 \times 10^{5}: 0.5 \times 10^{5}\right.$ cells $)$, and $4: 1$ $\left(1 \times 10^{5}: 0.25 \times 10^{5}\right.$ cells $)$ or alone in an anti-CD3 antibody-coated 96well plate for $72 \mathrm{~h}$. The assay was set up with four wells per experimental group. A colorimetric Cell Proliferation WST-1 Reagent (Roche, Basel, Switzerland) proliferation assay was performed by adding $10 \mu \mathrm{l}$ per $100 \mu \mathrm{l}$ of culture media and incubated for the last $4 \mathrm{~h}$ of the co-culture period, as previously reported. ${ }^{67-70}$ The absorbance was read at $420 \mathrm{~nm}$ with a reference wavelength of $600 \mathrm{~nm}$ according to the manufacturer's instructions. Inhibition of proliferation was calculated by subtraction of blank (media alone) and divided by the absorbance of Tresps cultured alone. Data are presented as the percentage of total proliferation of Tresps alone. Results presented are the combined results of three independent experiments.
Multiplex cytokine immunobead assay (Luminex). Serum samples from young or old mice $(n=10)$ or Treg assay supernatants (from three wells for each experimental group) were collected and cytokine production was determined by Luminex (Austin, TX) assay. Samples were added to wells containing the appropriate cytokine bead mixture that included mouse monoclonal antibodies specific for IL-4 IL-13, IFN- $\gamma$, and IL-17 (Upstate-Millipore, Billerica, MA). Serial dilutions of the above cytokines were added to wells in the same plate as the mouse samples to generate a standard curve. The plates were incubated overnight at $4{ }^{\circ} \mathrm{C}$ to capture the cytokines by the antibody-conjugated fluorescent beads. After three washes with assay buffer, $25 \mu \mathrm{l}$ of biotinylated secondary cytokine antibody mixture was applied for $1.5 \mathrm{~h}$ in the dark at room temperature. The reactions were detected with streptavidin-phycoerythrin using a Luminex 100 IS 2.3 system (Austin, TX). The limit of detection of this assay was $3.4 \mathrm{pg} \mathrm{ml}^{-1}$ for IFN- $\gamma, 3.4 \mathrm{pg} \mathrm{ml}^{-1}$ for IL-4, 3.75 $\mathrm{pg} \mathrm{ml}^{-1}$ for IL-13, and $3.19 \mathrm{pg} \mathrm{ml}^{-1}$ for IL-17.

Adoptive transfer experiments. $\mathrm{CD} 4{ }^{+} \mathrm{CD} 25^{+}$or $\mathrm{CD} 4{ }^{+} \mathrm{CD} 25^{-}$cells from 7-14-week-old or 45-50-week-old mice were isolated from the spleens and CLN as stated above. $\mathrm{CD} 4{ }^{+} \mathrm{CD} 25^{+}$or $\mathrm{CD} 4{ }^{+} \mathrm{CD} 25^{-}$cells $\left(2 \times 10^{6}\right)$ were transferred intraperitoneally to 8 -week-old T celldeficient recombination activating protein 1 (RAG1KO) mice. Experiments were performed 5 weeks after adoptive transfer of $\mathrm{CD} 4{ }^{+} \mathrm{CD} 25^{+}$or $\mathrm{CD} 4{ }^{+} \mathrm{CD} 25^{-}$cells. Each group contained three to four recipient mice.

Statistical analysis. Sample size and power calculations were performed using Statmate software (La Jolla, CA) based on preliminary studies. Statistical analyses were performed with Graph Pad Prism software (Graph Pad, version 6, La Jolla, CA). Data were first evaluated for normality with the Kolmogorov-Smirnov normality test. Appropriate parametric (two-way analysis of variance or $t$-test) or nonparametric (Mann-Whitney $U$ or Wilcoxon) statistical tests were used to make comparisons between two groups.

SUPPLEMENTARY MATERIAL is linked to the online version of the paper at http://www.nature.com/mi

\section{ACKNOWLEDGMENTS}

We thank Kevin Tesareski for technical assistance in performing experiments in this manuscript. We also thank Dr Krauss for providing some of the NOD.B10. $2^{b}$ mice at 100 weeks. This work was supported by Fight for Sight Grants-in-aid (to C.S.d.P.), EY018888 (to C.S.d.P.), NIH T32 (A1053831) (to F.B.), EY11915 (to S.C.P.), NIH Core grants EY002520 and EY020799, Research to Prevent Blindness, the Oshman Foundation, William Stamps Farish Fund, the Hamill Foundation, and by the Cytometry and Cell Sorting Core at Baylor College of Medicine that is funded by the $\mathrm{NIH}$ National Institute of Allergy and Infectious Diseases grants P30AI036211, NCI P30CA125123, and NCRR S10RR024574.

\section{AUTHOR CONTRIBUTIONS}

Terry G. Coursey: designed and performed experiments, analysis, and wrote a majority of the manuscript; Fang Bian, Mahira Zaheer, and Eugene A. Volpe: performed experiments and analysis and reviewed the manuscript;Stephen C. Pflugfelder: designed experiments and contributed to writing of the manuscript; Cintia S. de Paiva: designed and performed experiments, analysis, and co-wrote the manuscript.

\section{DISCLOSURE}

The authors declared no conflict of interest.

(c) 2017 Society for Mucosal Immunology

\section{REFERENCES}

1. Rocha, E.M., Alves, M., Rios, J.D. \& Dartt, D.A. The aging lacrimal gland: changes in structure and function. Ocul. Surf. 6, 162-174 (2008). 
2. Sergiev, P.V., Dontsova, O. A. \& Berezkin, G.V. Theories of aging: an everevolving field. Acta Naturae 7, 9-18 (2015).

3. Cohen, A.A. Complex systems dynamics in aging: new evidence, continuing questions. Biogerontology 17, 205-220 (2015).

4. Fulop, T., Witkowski, J.M., Pawelec, G., Alan, C. \& Larbi, A. On the immunological theory of aging. Interdiscip. Top. Gerontol. 39, 163-176 (2014).

5. Castelo-Branco, C. \& Soveral, I. The immune system and aging: a review. Gynecol. Endocrinol. 30, 16-22 (2014).

6. DeVeale, B., Brummel, T. \& Seroude, L. Immunity and aging: the enemy within?. Aging Cell 3, 195-208 (2004).

7. Schaumberg, D.A., Sullivan, D.A., Buring, J.E. \& Dana, M.R. Prevalence of dry eye syndrome among US women. Am. J. Ophthalmol. 136, 318-326 (2003).

8. Schaumberg, D.A., Dana, R., Buring, J.E. \& Sullivan, D.A. Prevalence of dry eye disease among US men: estimates from the Physicians' Health Studies. Arch. Ophthalmol. 127, 763-768 (2009).

9. Damato, B.E., Allan, D., Murray, S.B. \& Lee, W.R. Senile atrophy of the human lacrimal gland: the contribution of chronic inflammatory disease. $\mathrm{Br}$. J. Ophthalmol. 68, 674-680 (1984).

10. Benson, W.R. Accerleration of aging changes in the exorbital lacrimal gland of the female rat. Am. J. Pathol. 45, 587-597 (1964).

11. Draper, C.E., Adeghate, E., Lawrence, P.A., Pallot, D.J., Garner, A. \& Singh, $J$. Age-related changes in morphology and secretory responses of male rat lacrimal gland. J. Auton. Nerv. Syst. 69, 173-183 (1998).

12. Williams, R.M., Singh, J. \& Sharkey, K.A. Innervation and mast cells of the rat lacrimal gland: the effects of age. Adv. Exp. Med. Biol. 350, 67-74 (1994).

13. McClellan, A.J. et al. Ocular surface disease and dacryoadenitis in aging C57BL/6 mice. Am. J. Pathol. 184, 631-643 (2014).

14. Thomas, D.C., Mellanby, R.J., Phillips, J.M. \& Cooke, A. An early agerelated increase in the frequency of CD4 + Foxp3 + cells in BDC2.5NOD mice. Immunology 121, 565-576 (2007).

15. Zhao, L., Sun, L., Wang, H., Ma, H., Liu, G. \& Zhao, Y. Changes of CD4 + CD25 + Foxp3 + regulatory Tcells in aged Balb/c mice. J. Leukoc. Biol. 81, 1386-1394 (2007).

16. de Paiva, C.S. et al. IL-17 disrupts corneal barrier following desiccating stress. Mucosal Immunol. 2, 243-253 (2009).

17. Chauhan, S.K. et al. Autoimmunity in dry eye is due to resistance of Th17 to Treg suppression. J. Immunol. 182, 1247-1252 (2009).

18. Zheng, X., de Paiva, C.S., Li, D.Q., Farley, W.J. \& Pflugfelder, S.C. Desiccating stress promotion of Th17 differentiation by ocular surface tissues through a dendritic cell-mediated pathway. Invest Ophthalmol. Vis. Sci. 51, 3083-3091 (2010).

19. Zhang, X. et al. NK cells promote Th-17 mediated corneal barrier disruption in dry eye. PLoS One 7, e36822 (2012).

20. Guo, J. \& Zhou, X. Regulatory T cells turn pathogenic. Cell Mol. Immunol. 12, 525-532 (2015)

21. Grant, C.R., Liberal, R., Mieli-Vergani, G., Vergani, D. \& Longhi, M.S. Regulatory T-cells in autoimmune diseases: challenges, controversies and-yet-unanswered questions. Autoimmun. Rev. 14, 105-116 (2015).

22. Li, X. \& Zheng, Y. Regulatory T cell identity: formation and maintenance. Trends Immunol. 36, 344-353 (2015).

23. Nishioka, T., Shimizu, J., lida, R., Yamazaki, S. \& Sakaguchi, S. CD4+ CD25 + Foxp3 + Tcells and CD4 + CD25-Foxp3 + Tcells in aged mice. J. Immunol. 176, 6586-6593 (2006).

24. Schmitt, V., Rink, L. \& Uciechowski, P. The Th17/Treg balance is disturbed during aging. Exp. Gerontol. 48, 1379-1386 (2013).

25. Komatsu, N. etal. Pathogenic conversion of Foxp3 + Tcells into TH17 cells in autoimmune arthritis. Nat. Med. 20, 62-68 (2014).

26. Kryczek, I. et al. IL-17 + regulatory T cells in the microenvironments of chronic inflammation and cancer. J. Immunol. 186, 4388-4395 (2011).

27. Du, R., Zhao, H., Yan, F. \& Li, H. IL-17 + Foxp3 + T cells: an intermediate differentiation stage between Th17 cells and regulatory T cells. J. Leukoc. Biol. 96, 39-48 (2014).

28. Nguyen, C.Q. \& Peck, A.B. Unraveling the pathophysiology of Sjogren syndrome-associated dry eye disease. Ocul. Surf. 7, 11-27 (2009).

29. Cha, S., Peck, A.B. \& Humphreys-Beher, M.G. Progress in understanding autoimmune exocrinopathy using the non-obese diabetic mouse: an update. Crit Rev. Oral Biol. Med. 13, 5-16 (2002).
30. Jabs, D.A. et al. Autoimmune Th2-mediated dacryoadenitis in MRL/MpJ mice becomes Th1-mediated in IL-4 deficient MRL/MpJ mice. Invest Ophthalmol. Vis. Sci. 48, 5624-5629 (2007).

31. Rahimy, E. et al. Spontaneous autoimmune dacryoadenitis in aged CD25KO mice. Am J Pathol. 177, 744-753 (2010).

32. Yoon, K.C. et al. Desiccating environmental stress exacerbates autoimmune lacrimal keratoconjunctivitis in non-obese diabetic mice. J. Autoimmun. 30, 212-221 (2008).

33. Niederkorn, J.Y. et al. Desiccating stress induces t cell-mediated Sjogren's syndrome-like lacrimal keratoconjunctivitis. J. Immunol. 176, 3950-3957 (2006).

34. de Paiva, C.S. et al. IFN- $\gamma$ promotes goblet cell loss in response to desiccating ocular stress.. Invest. Ophthalmol. Vis. Sci. 47: E-Abstract 5579 (2006)

35. Coursey, T.G., Gandhi, N.B., Volpe, E.A., Pflugfelder, S.C. \& de Paiva, C.S. Chemokine receptors CCR6 and CXCR3 are necessary for CD4(+) $T$ cell mediated ocular surface disease in experimental dry eye disease. PLoS One 8, e78508 (2013).

36. Ayyoub, M. etal. Human memory FOXP3 + Tregs secrete IL-17 ex vivo and constitutively express the $T(H) 17$ lineage-specific transcription factor RORgamma t. Proc. Natl. Acad. Sci. USA 106, 8635-8640 (2009).

37. Voo, K.S. et al. Identification of IL-17-producing FOXP3 + regulatory Tcells in humans. Proc. Natl. Acad. Sci. USA 106, 4793-4798 (2009).

38. Zhang, $X$. et al. Interferon-\{gamma\} exacerbates dry eye induced apoptosis in conjunctiva via dual apoptotic pathways. Invest. Ophthalmol. Vis. Sci. 52, 6279-6285 (2011).

39. de Paiva, C.S. et al. Dry eye-induced conjunctival epithelial squamous metaplasia is modulated by interferon-\{gamma\}. Invest. Ophthalmol. Vis. Sci. 48, 2553-2560 (2007).

40. Schaumburg, C.S. et al. Ocular surface APCs are necessary for autoreactive T cell-mediated experimental autoimmune lacrimal keratoconjunctivitis. J. Immunol. 187, 3653-3662 (2011).

41. Toda, I., Sullivan, B.D., Rocha, E.M., da Silveira, L.A., Wickham, L.A. \& Sullivan, D.A. Impact of gender on exocrine gland inflammation in mouse models of Sjogren's syndrome. Exp. Eye Res. 69, 355-366 (1999).

42. Robinson, C. P. et al. A novel NOD-derived murine model of primary Sjogren's syndrome. Arthritis Rheum. 41, 150-156 (1998).

43. Zhang, $X$. et al. Desiccating stress induces CD4(+) T-cell-mediated Sjogren's syndrome-like corneal epithelial apoptosis via activation of the extrinsic apoptotic pathway by interferon-gamma. Am. J. Pathol. 179, 1807-1814 (2011).

44. Zhang, X., de Paiva, C.S., Su, Z., Volpe, E.A., Li, D.Q. \& Pflugfelder, S.C. Topical interferon-gamma neutralization prevents conjunctival goblet cell loss in experimental murine dry eye. Exp. Eye Res. 118, 117-124 (2014).

45. Coursey, T.G., Tukler, H.J., Barbosa, F.L., de Paiva, C.S. \& Pflugfelder, S.C. Interferon-gamma-induced unfolded protein response in conjunctival goblet cells as a cause of mucin deficiency in Sjogren syndrome. Am. J. Pathol. 186, 1547-1558 (2016).

46. Furukawa, R.E. \& Polse, K.A. Changes in tear flow accompanying aging. Am. J. Optom. Physiol Opt. 55, 69-74 (1978).

47. Patel, S. \& Wallace, I. Tear meniscus height, lower punctum lacrimale, and the tear lipid layer in normal aging. Optom. Vis. Sci. 83, 731-739 (2006).

48. Mathers, W.D., Lane, J.A. \& Zimmerman, M.B. Tear film changes associated with normal aging. Cornea 15, 229-334 (1996).

49. Kojima, T. et al. Age-related dysfunction of the lacrimal gland and oxidative stress: evidence from the Cu,Zn-superoxide dismutase-1 (Sod1) knockout mice. Am. J. Pathol. 180, 1879-1896 (2012).

50. Marko, C.K., Menon, B.B., Chen, G., Whitsett, J.A., Clevers, H. \& Gipson, I. K. Spdef null mice lack conjunctival goblet cells and provide a model of dry eye. Am. J. Pathol. 183, 35-48 (2013).

51. Modulo, C.M. et al. The role of dyslipidemia on ocular surface, lacrimal and meibomian gland structure and function. Curr. Eye Res. 37, 300-308 (2012).

52. You, I.C., Bian, F., Volpe, E.A., de Paiva, C.S. \& Pflugfelder, S.C. Agerelated conjunctival disease in the C57BL/6.NOD-Aec1Aec2 mouse model of Sjogren syndrome develops independent of lacrimal dysfunction. Invest. Ophthalmol. Vis. Sci. 56, 2224-2233 (2015).

53. Nasu, M., Matsubara, O. \& Yamamoto, H. Post-mortem prevalence of lymphocytic infiltration of the lacrymal gland: a comparative study in autoimmune and non-autoimmune diseases. J. Pathol. 143, 11-15 (1984). 
54. Draper, C.E., Adeghate, E.A., Singh, J. \& Pallot, D.J. Evidence to suggest morphological and physiological alterations of lacrimal gland acini with ageing. Exp. Eye Res. 68, 265-276 (1999).

55. Jagger, A., Shimojima, Y., Goronzy, J.J. \& Weyand, C.M. Regulatory Tcells and the immune aging process: a mini-review. Gerontology 60, 130-137 (2014).

56. Chiu, B.C., Stolberg, V.R., Zhang, H. \& Chensue, S.W. Increased Foxp3(+) Treg cell activity reduces dendritic cell co-stimulatory molecule expression in aged mice. Mech. Ageing Dev. 128, 618-627 (2007).

57. Sharma, S., Dominguez, A.L. \& Lustgarten, J. High accumulation of $T$ regulatory cells prevents the activation of immune responses in aged animals. J. Immunol. 177, 8348-8355 (2006).

58. Lages, C.S. et al. Functional regulatory T cells accumulate in aged hosts and promote chronic infectious disease reactivation. J. Immunol. 181, 1835-1848 (2008).

59. Christodoulou, M.I., Kapsogeorgou, E.K., Moutsopoulos, N.M. \& Moutsopoulos, H.M. Foxp3 + T-regulatory cells in Sjogren's syndrome: correlation with the grade of the autoimmune lesion and certain adverse prognostic factors. Am. J. Pathol. 173, 1389-1396 (2008).

60. Sarigul, M. et al. The numbers of Foxp3 + Treg cells are positively correlated with higher grade of infiltration at the salivary glands in primary Sjogren's syndrome. Lupus 19, 138-145 (2010).

61. Raynor, J., Lages, C.S., Shehata, H., Hildeman, D.A. \& Chougnet, C.A. Homeostasis and function of regulatory $T$ cells in aging. Curr. Opin. Immunol. 24, 482-487 (2012).

62. Feng, T., Cao, A.T., Weaver, C.T., Elson, C.O. \& Cong, Y. Interleukin-12 converts Foxp3 + regulatory $T$ cells to interferon-gamma-producing
Foxp3 + T cells that inhibit colitis. Gastroenterology 140, 2031-2043 (2011).

63. Koenecke, C. et al. IFN-gamma production by allogeneic Foxp3+ regulatory $T$ cells is essential for preventing experimental graft-versushost disease. J. Immunol. 189, 2890-2896 (2012).

64. Pitcher, J. III et al. Pharmacological cholinergic blockade stimulates inflammatory cytokine production and lymphocytic infiltration in the mouse lacrimal gland. Invest. Ophthalmol. Vis. Sci. 52, 3221-3227 (2011).

65. Stewart, P., Chen, Z., Farley, W., Olmos, L. \& Pflugfelder, S.C. Effect of experimental dry eye on tear sodium concentration in the mouse. Eye Contact Lens 31, 175-178 (2005).

66. White, S.C. \& Casarett, G.W. Induction of experimental autoallergic sialadenitis. J. Immunol. 112, 178-185 (1974).

67. Lau, K.M. et al. Increase in circulating Foxp3 + CD4 + CD25(high) regulatory $\mathrm{T}$ cells in nasopharyngeal carcinoma patients. Br. J. Cancer 96, 617-622 (2007).

68. Dannull, J., Schneider, T., Lee, W.T., de, R.N., Tyler, D.S. \& Pruitt, S.K. Leukotriene $\mathrm{C} 4$ induces migration of human monocyte-derived dendritic cells without loss of immunostimulatory function. Blood 119, 3113-3122 (2012).

69. Gulden, E. et al. Toll-like receptor 4 deficiency accelerates the development of insulin-deficient diabetes in non-obese diabetic mice. PLoS One 8, e75385 (2013).

70. Qing, K., Weifeng, W., Fan, Y., Yuluan, Y., Yu, P. \& Yanlan, H. Distinct different expression of Th17 and Th9 cells in coxsackie virus B3-induced mice viral myocarditis. Virol. J. 8, 267 (2011). 